ص ص ص [rri-rol

أثر شفافية أنظمة المعلومات في تعزيز مكانة العاملين

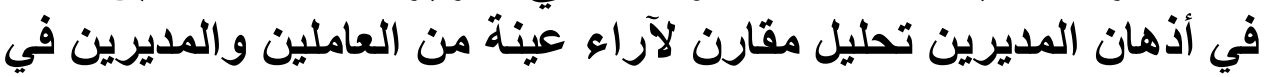

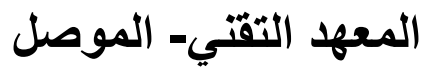

$$
\begin{aligned}
& \text { الدكتور عبد الستار محمد علي العدواني } \\
& \text { أستاذ مساعد- قسم نظم المعلومات الإدارية }
\end{aligned}
$$

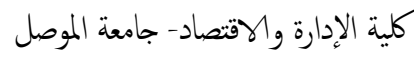

$$
\begin{aligned}
& \text { Dr.aladwani@yahoo.com }
\end{aligned}
$$

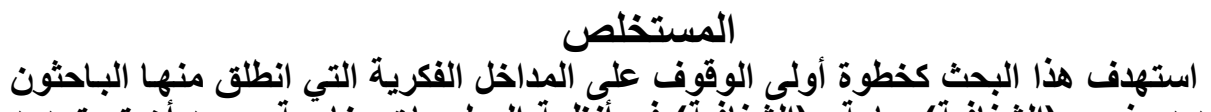

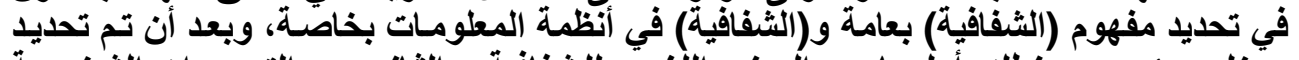

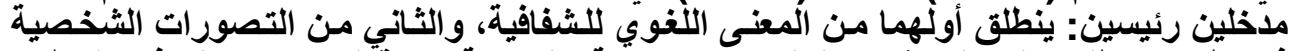

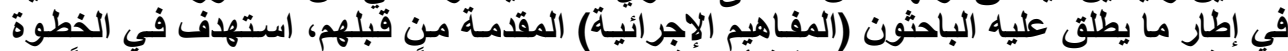

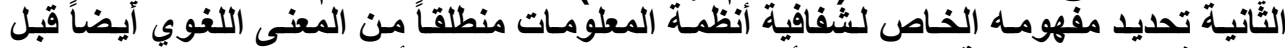

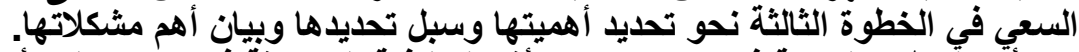

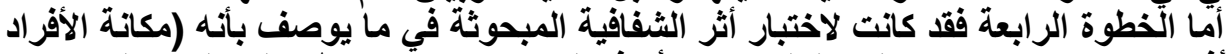

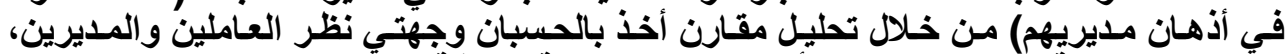

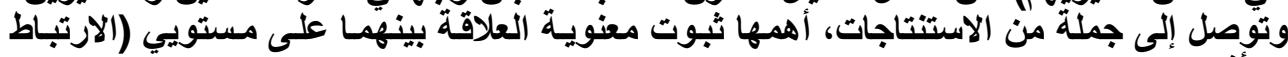

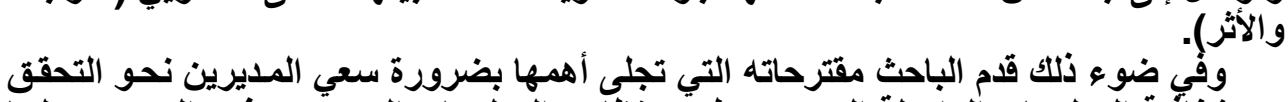

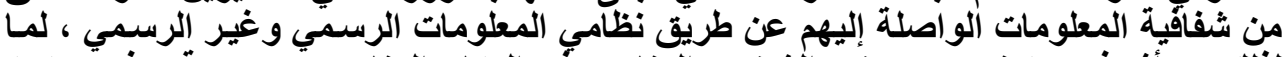

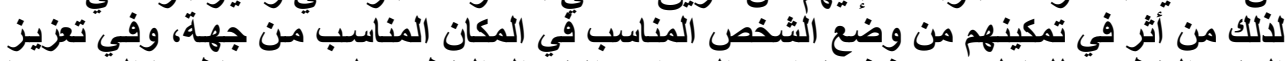

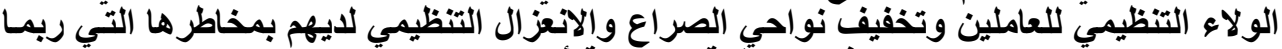

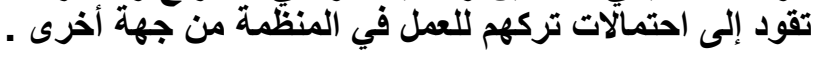


الدكتور العدواني [ror] [ب]

\title{
Effect Of Information Systems Transparency in Enhancing Employee Status in Managers Mind \\ Analysis comparative for opinions of sample of employee and managers in technical institute-Mosul
}

Abdul Sattar M. Al-Odwani (PhD)

Assistant Professor

Department of Management Information Systems

University of Mosul

\begin{abstract}
This study aims to capture the intellectual approaches from which the authors begin to define their transparency concept in general, especially the transparency of information system and after defining two main entries: the first came from the linguistic meaning of transparency, and the second came from the personal imaginations in the framework of what authors called the procedural concepts-presented by them. In the second step, the study defined its special concepts which begin from the linguistic meaning.

In the third step, the importance of transparency has been defined, the techniques of defining it, and its important problems. In fourth step the impact in what is called intellectual situation has been examine for people with respect to their directors through a comparative analysis putting in mind the views of both directors and personnel and concluded several results. The most important among them is the significant relation (the correlation and impact). The research introduced some recommendations, the more important of which is the necessity of seeking to preserving the transparency of information received through the formal and informal information systems. It has an important influence in enabling directors to put the right person in the right position on one hand, and in the other hand it enhances the organizational loyalty, mitigating the organizational conflicts and the risks may lead them to leave job in the organization.
\end{abstract}

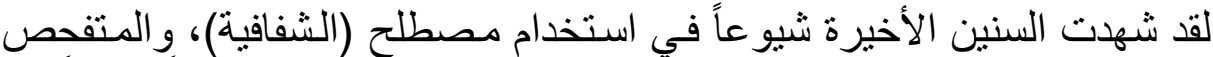

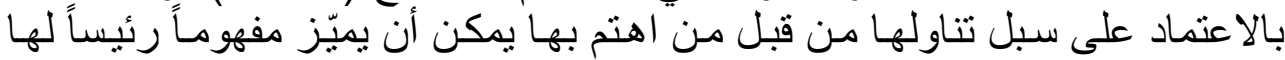

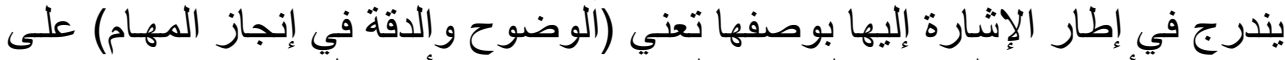

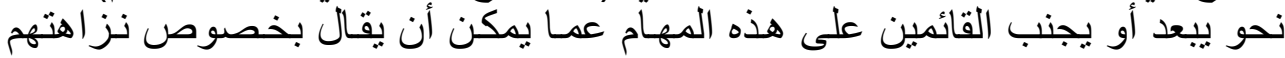

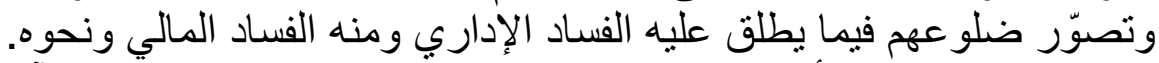

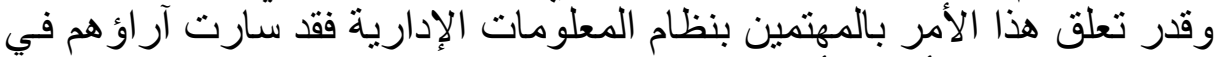

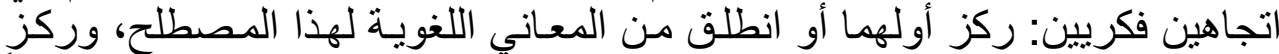

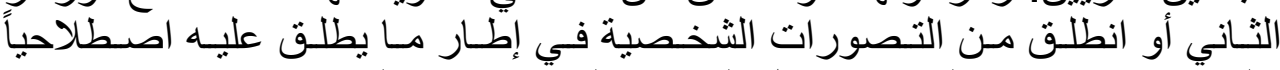

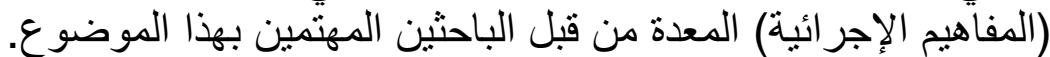

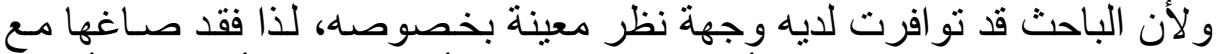

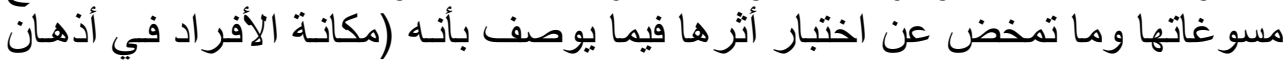

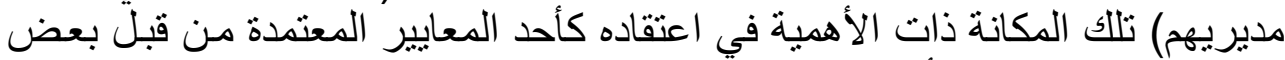

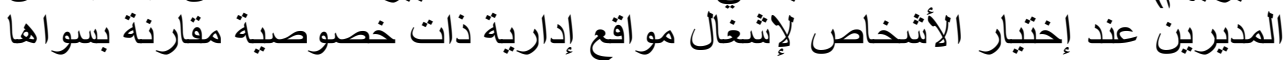

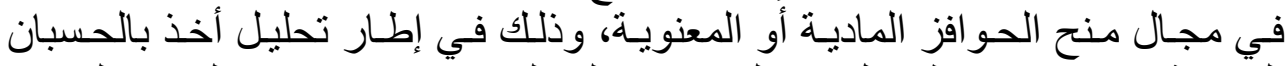

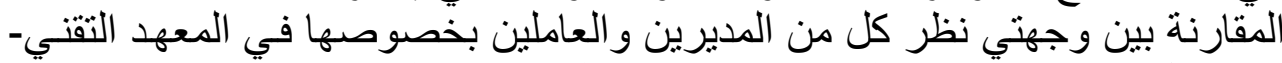

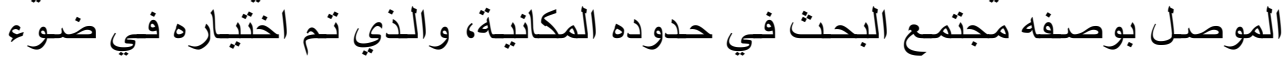




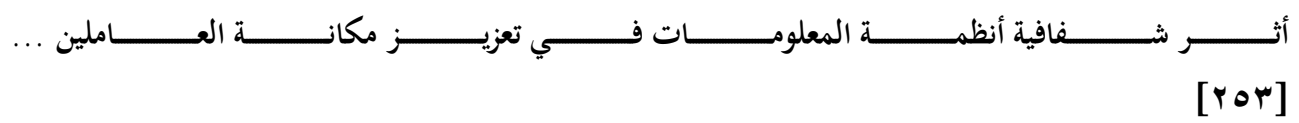

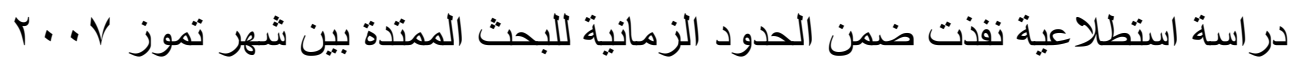

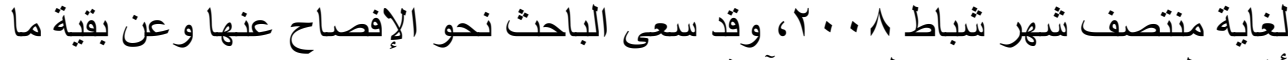
أشثار إليه في محاور هذا البحث الآتية:

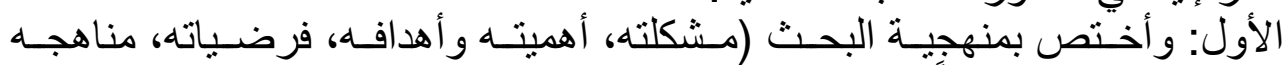

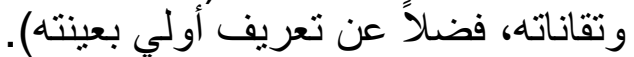

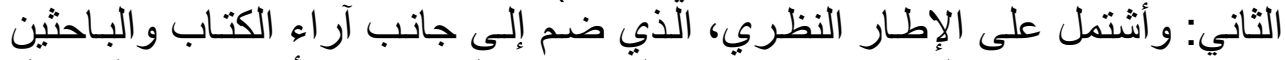

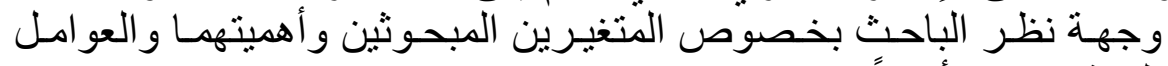
المؤثرة فيهما أيضاً.

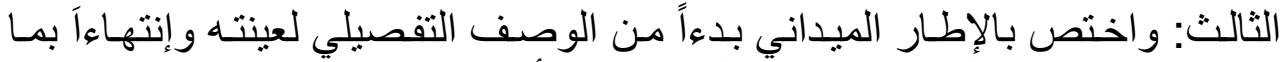

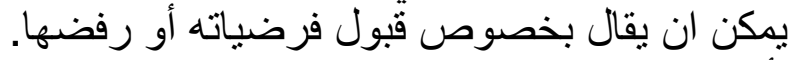

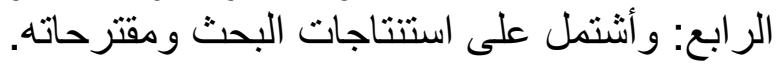

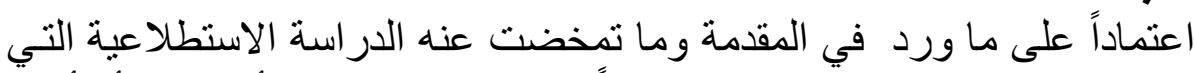
منهجية البحث البه مشكلة البحث البث

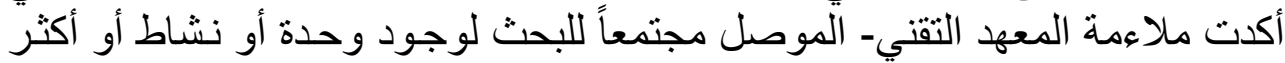

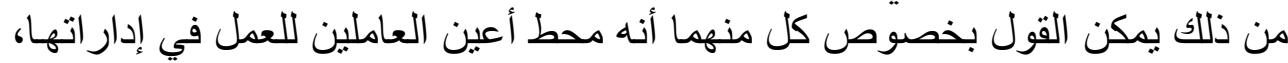

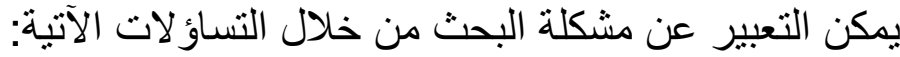

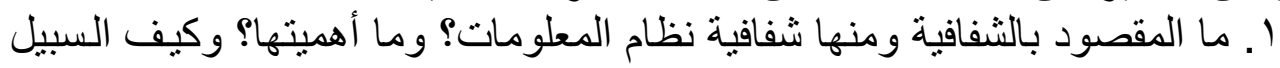

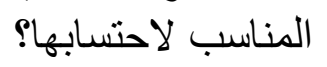

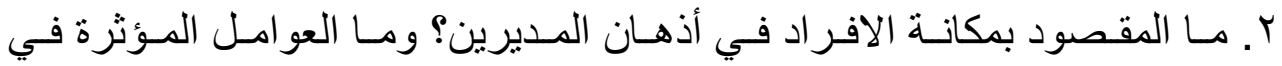
تحديدها؟

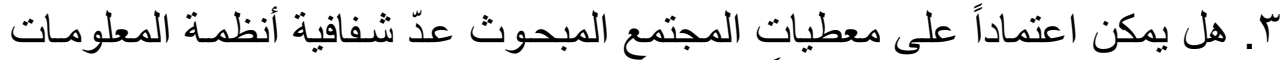

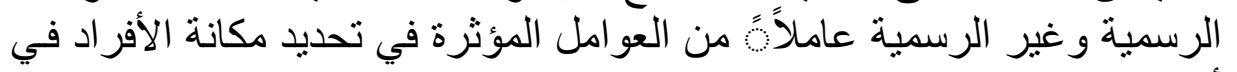
أذهان مديريهم?

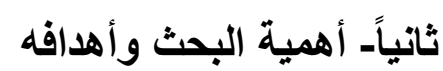

تبرز أهمية هذا البحث من أهمية أهدافه التي يمكن حصر ها في جانبين هما:

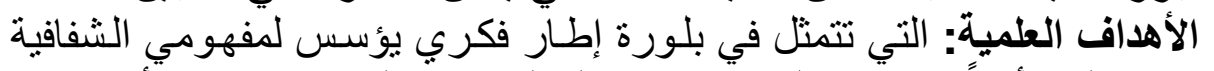

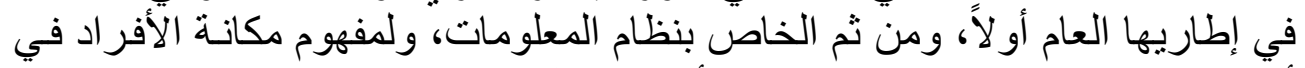

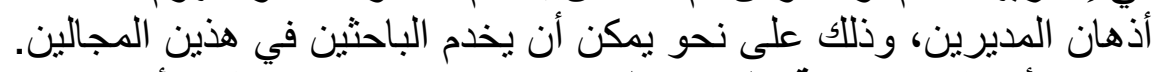

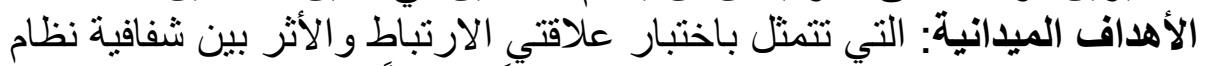

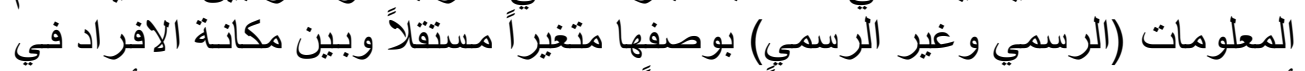

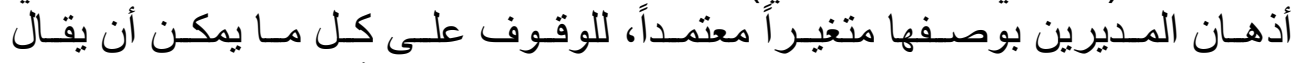

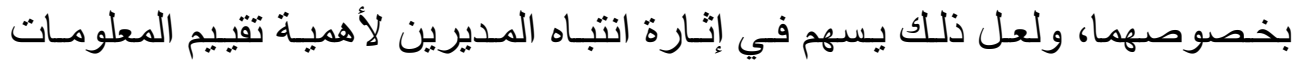

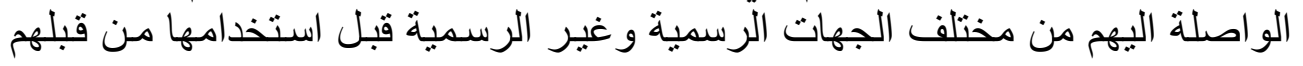




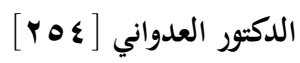

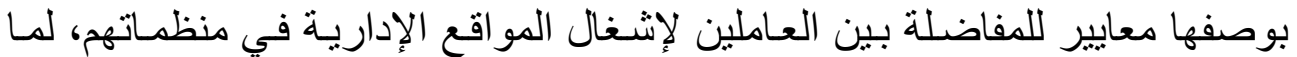

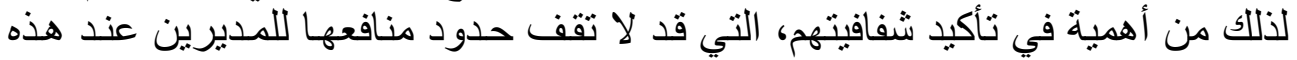

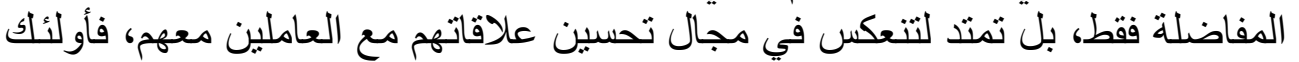

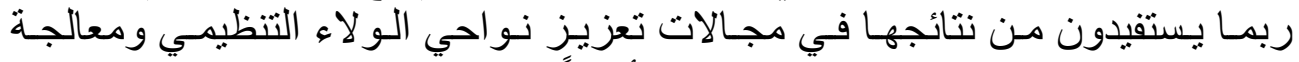
نواحي الصر اعات و العزلة التنظيمية لديهم أيضاً.

ثالثاء فرضيات البحث

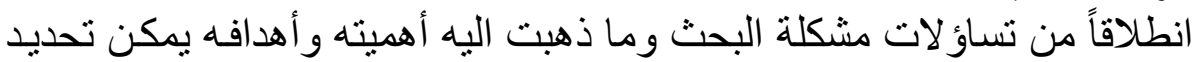

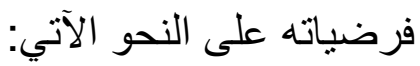

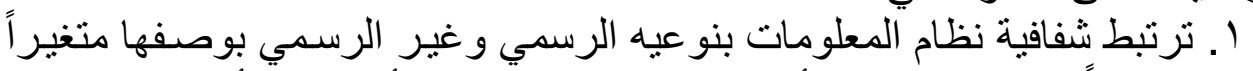

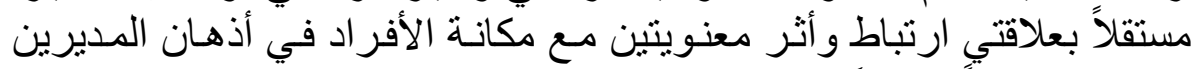

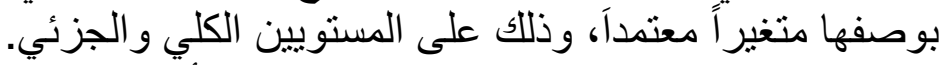

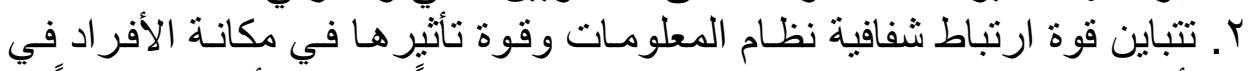

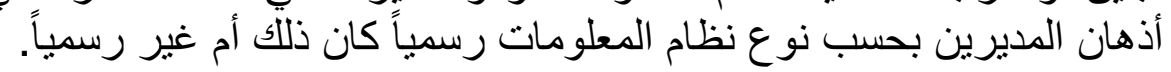

\section{رابعاً- منهج البحث وتقاناته وعينته}

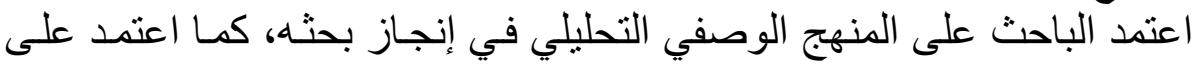

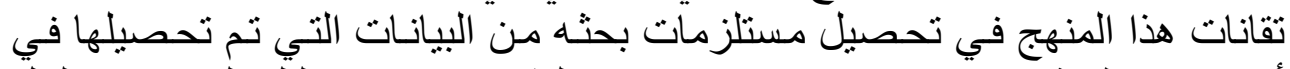

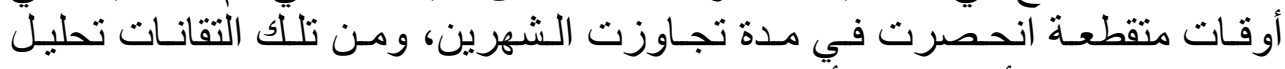

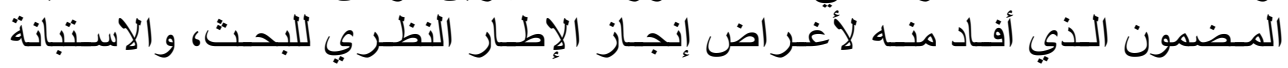

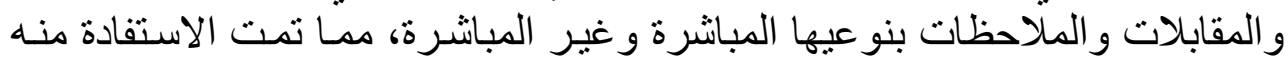

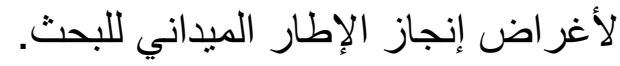

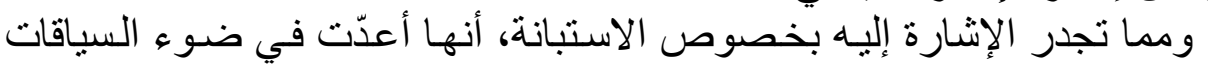

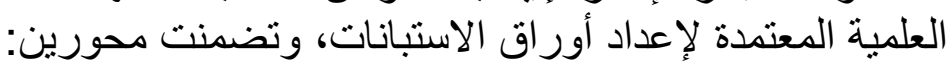

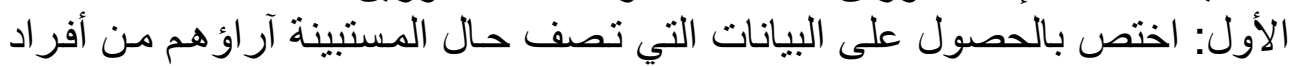

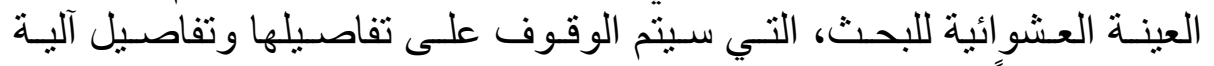
تحديدها لاحقاً. الثاني: اختص بالحصول على البيانات عن متغيري البحث (الثفأ الثفية ومكانة الأفراد)،

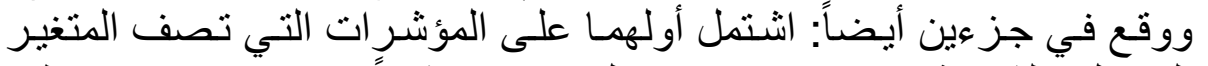

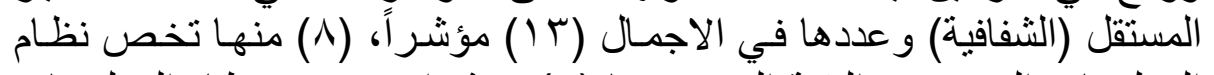

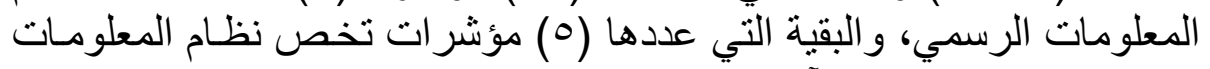

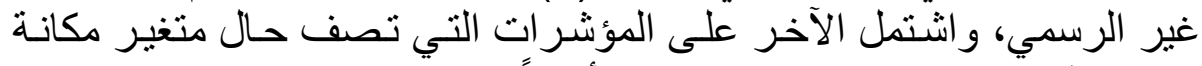

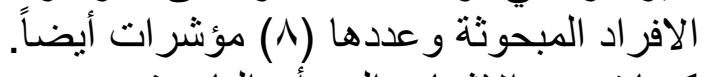

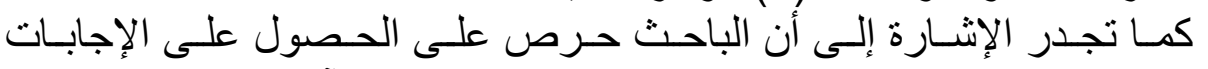

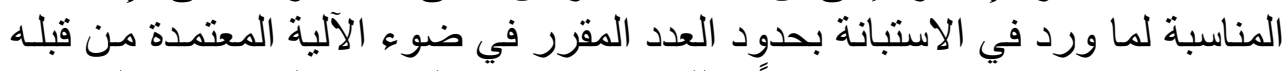

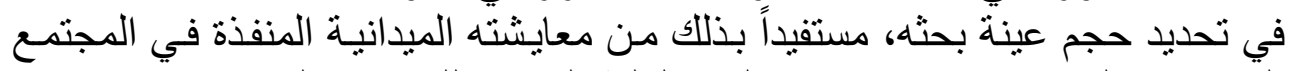

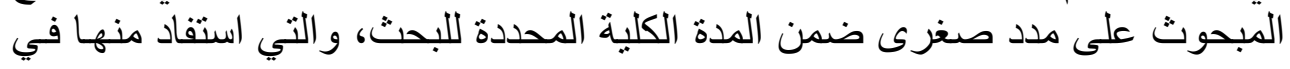




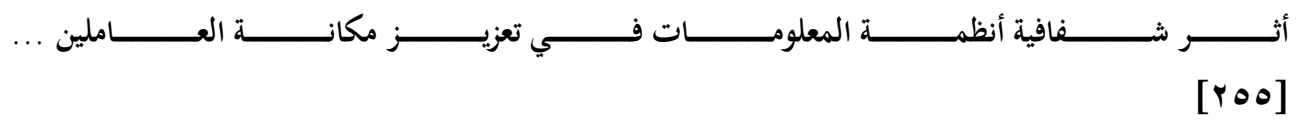

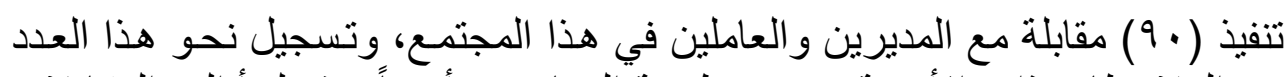

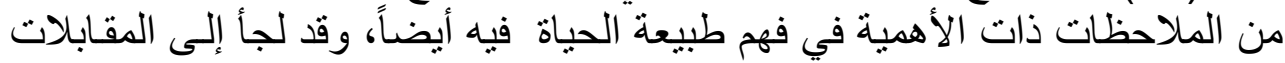
و الملاحظات للمسوغات المات الآتية:

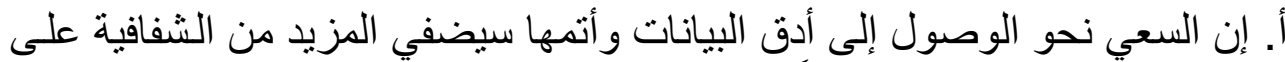

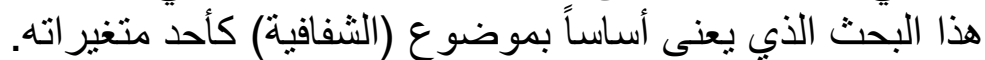

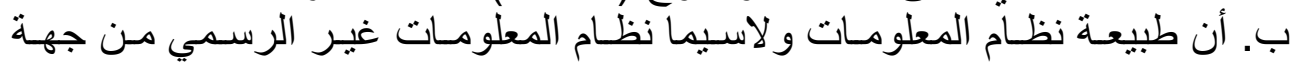

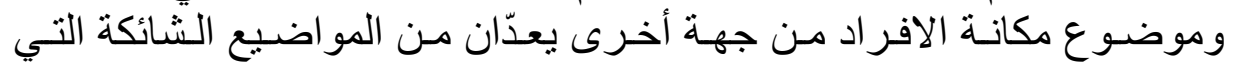

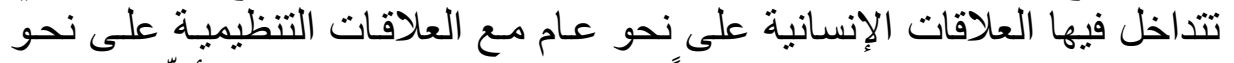

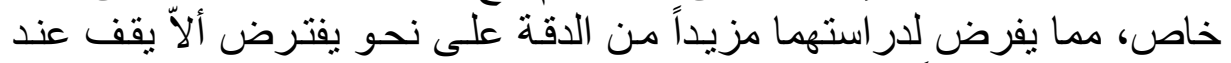

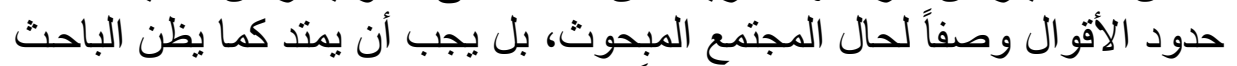

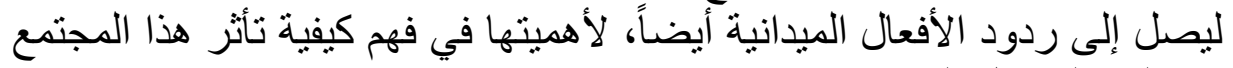
بمختلف العو امل البيئية.

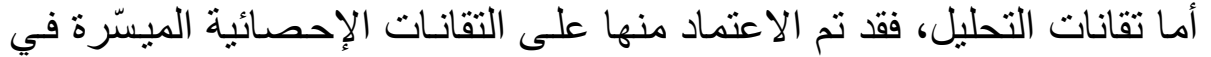

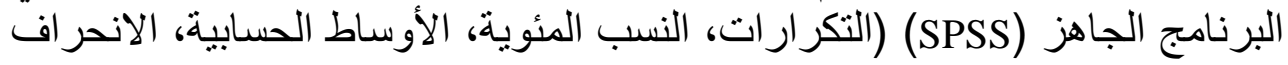

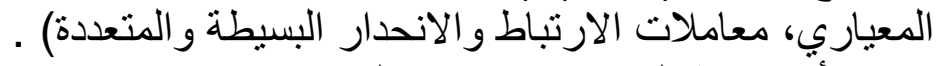

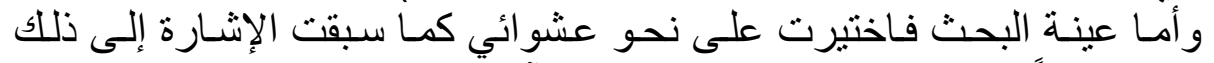

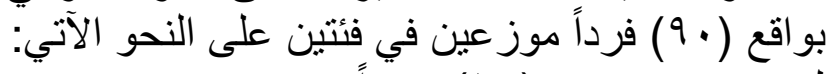

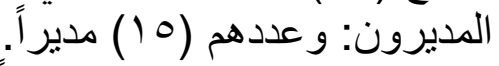

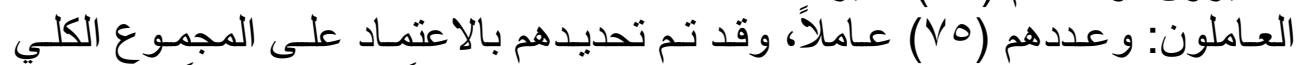

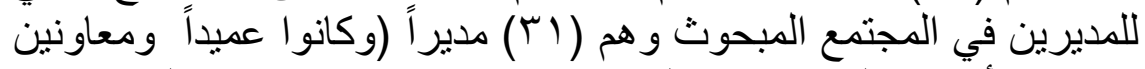

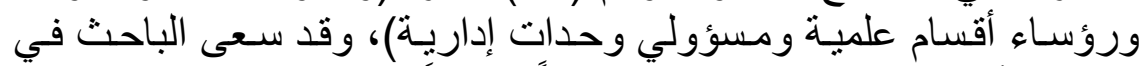

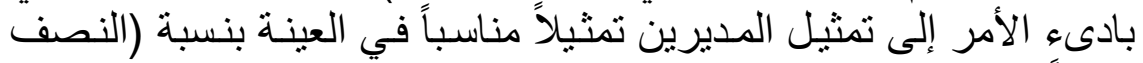

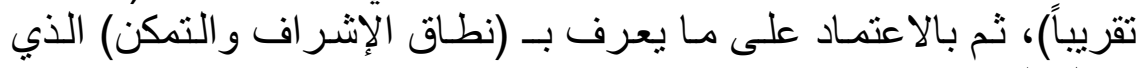

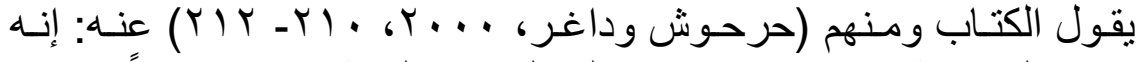
يقوم على نسبة (:0 تم تحديد عدد العاملين في العينة بـ (V0) فرداً. 


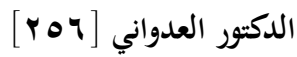

ا ـ المداخل الفكرية والمفاهيم

يمكن القول بتو افر مدخلين رئيسين تم في إطار هما تحديد (مفهوم الثفافية) في

نظام المعلومات هما:

الأول: ينطلق أو بستند على المعـاني اللغويـة لهذا المفهوم بوصفه مصدر اً صناعياً

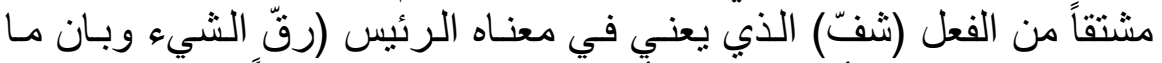

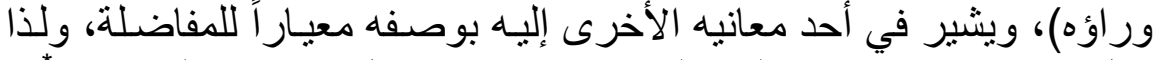

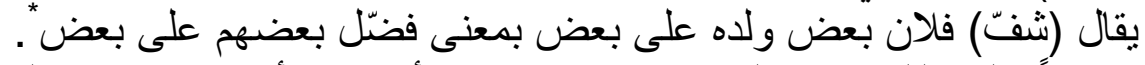

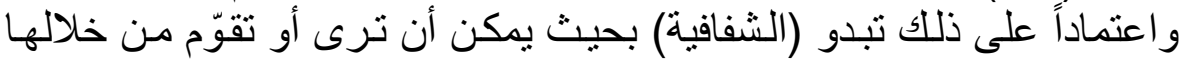

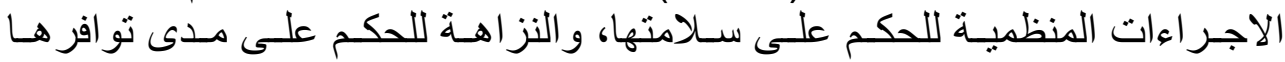

و الفاعلية للحكم على قوتها و هكذا

ولعل من الباحثين و الكنّاب الذين سكارو النها على هذا النهج (Nihal, 2001, 31)

و (Vishulanth\& Kaufmann, 1999, 3)

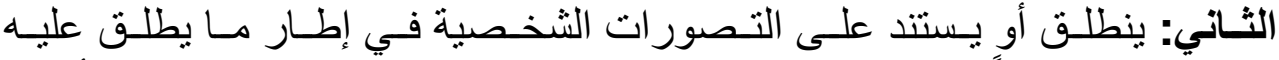
إصطلاحياً (المفاهيم الإجر ائية) المقدمة من قبل المرتمين بهذا المفهوم أمثنال (Tarca, 2001, 9) و الذي أشـار إليه بوصفيه (Fung \& et.al., 2005, 1)

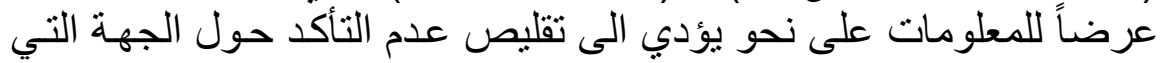

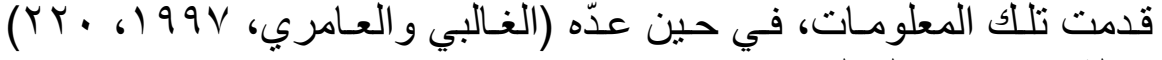

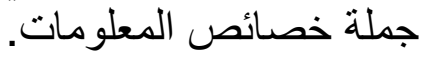
أما من وجهة نظر الباحث..... فعلى الر غم من إقر اره بأهمية بعض المهات المفاهيم

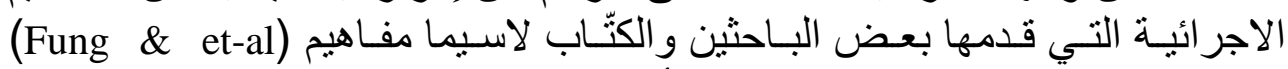

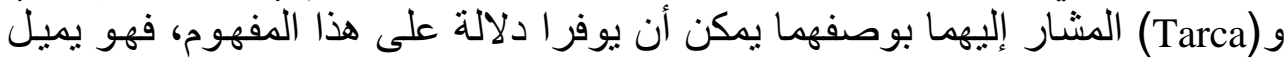
إلى ترجيح الاتجاه الأول، ويعزى ذلإن لإن لما مفاده الآتي:

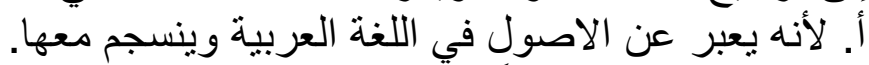

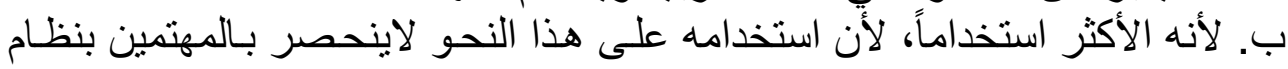

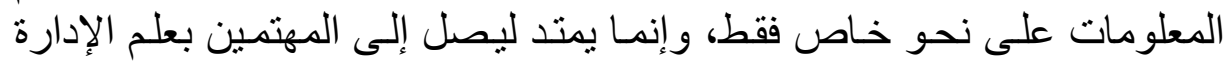

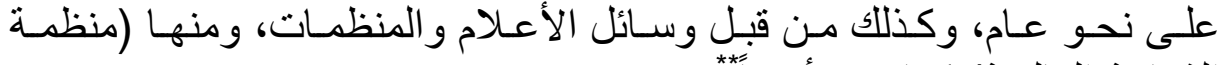

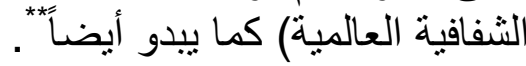

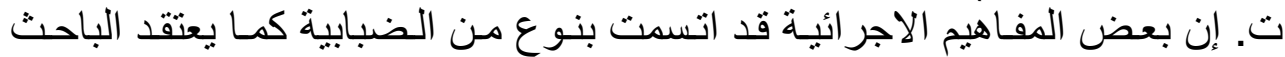

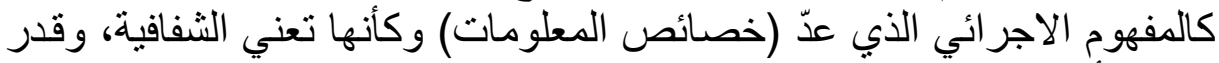

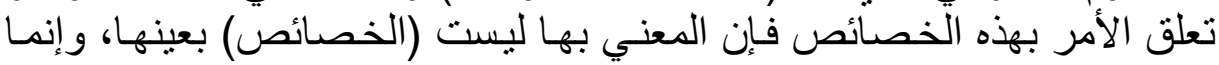
مدى قوة ظهور ها في مخرجات (معلومـات) النظام المر اد تقويم شفافيته بدليل

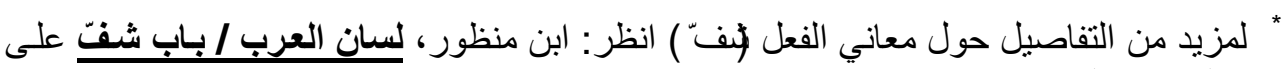
الموقع الالكتروني WWW.alwarak.com

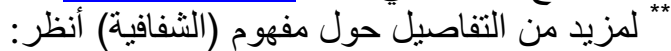

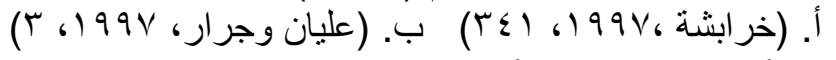
ت. ت. (Basle,1998,12-25) .www.transparency.org. ج 


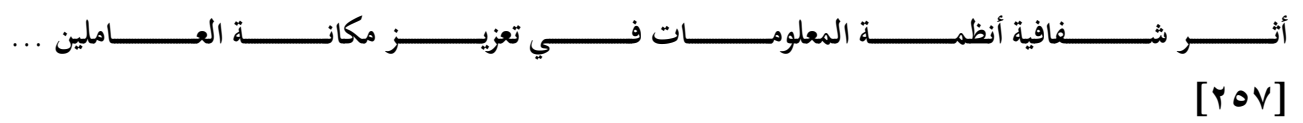

الدر اسة المشار إليها نفسها، ومعظم الدر اسـات إن لـم نقل جميع الدر اسـات التي التي تعتمد علي المنهج الوصفي في در اسة الظو اهر الهر المنظمية.

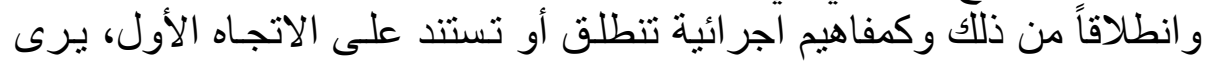

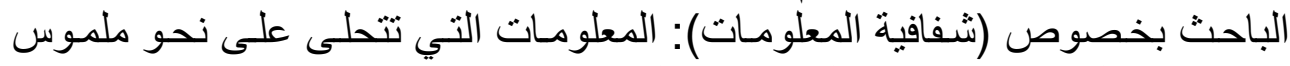

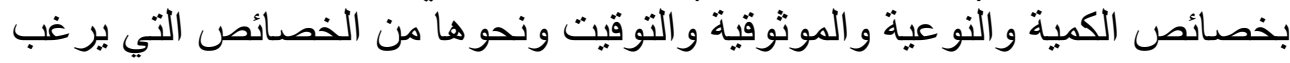

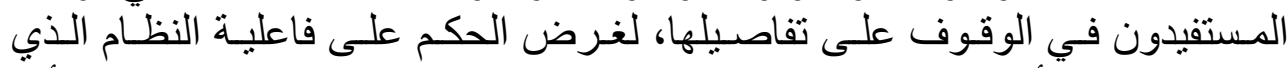

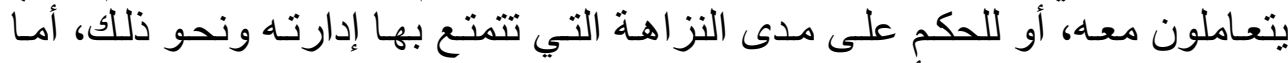

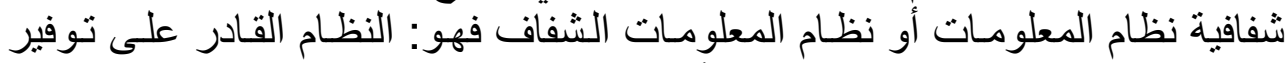

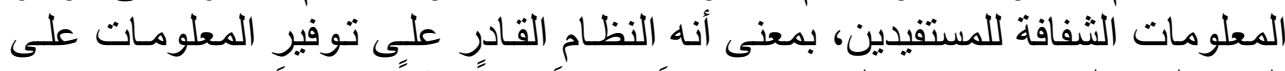

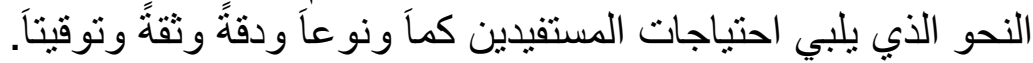

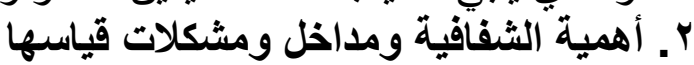

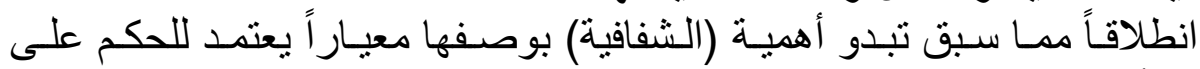
الظواهر أو المتغيرات المنظمية، ومنها على سبيل الامثلة (الفاعلية التنظيمية وفاعلية

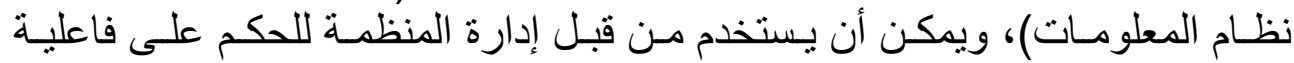

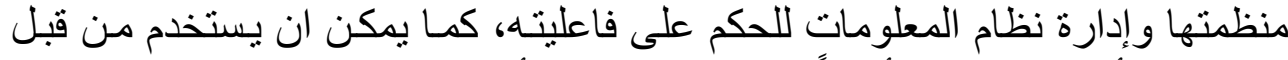

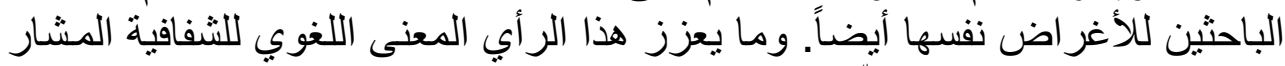

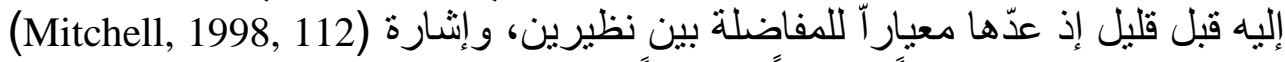

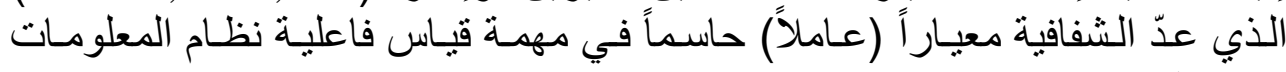
الإدارية.

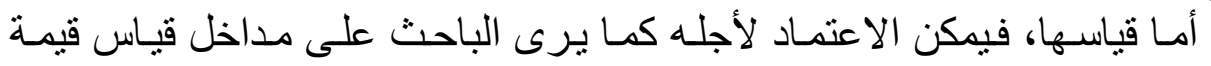

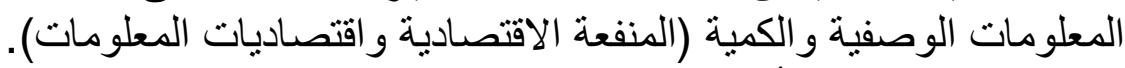

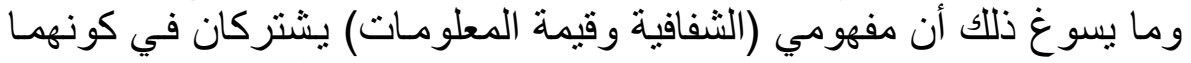

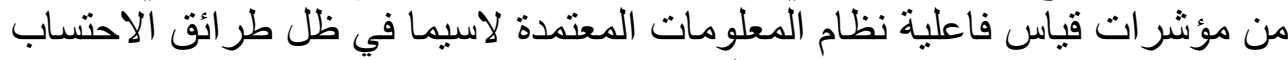

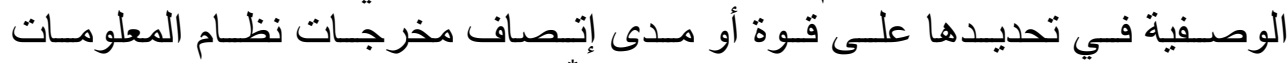
بالخصائص على وفق ما بر غب به به المستفيدون أ.

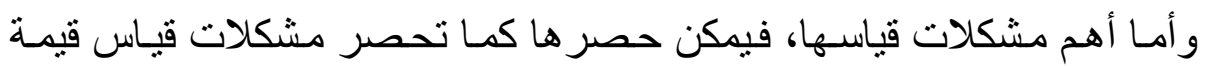

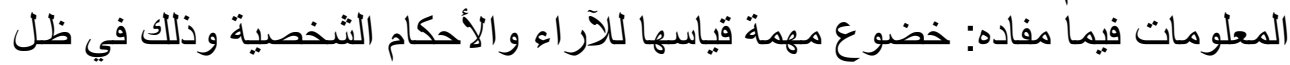

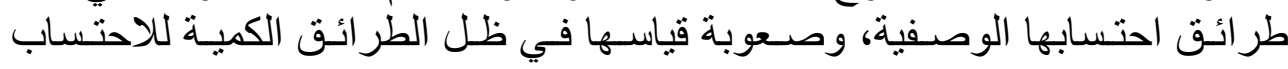
المشار إليها.

* للإطلاع على مفهوم قيمة المعلومات وسبل تحديدها و أهم مشكلاتها أنظر :

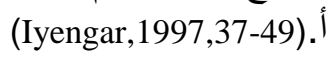

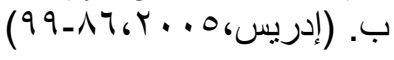




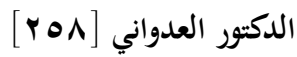

ثانياً- مكانة الإفراد في أذهان المديرين وأهميتها والعوامل المؤثرة في تحديدها

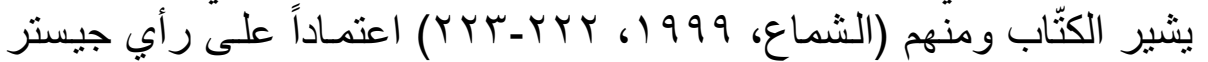
بارنرد و آخرين إلى نو افر ثنلاثة أنواع من المكانة بوصفها موقع ودرجة احتر ام الفرد

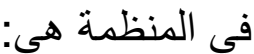

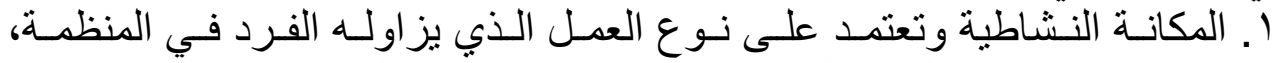

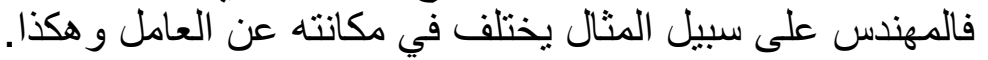
Y. المكانة الهرمية وتعتمد على المستوى الاداري الذي يعمل فيه.

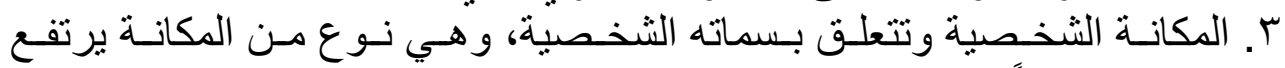

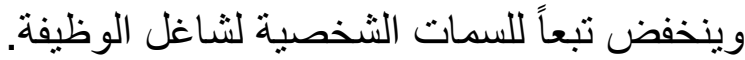

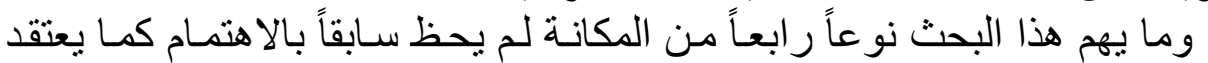

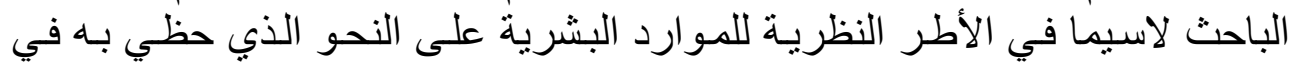

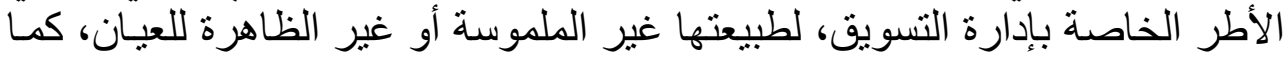

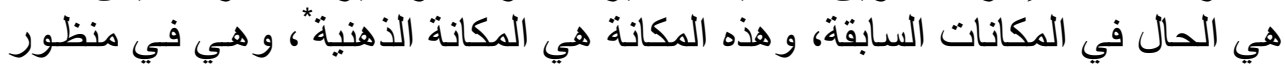

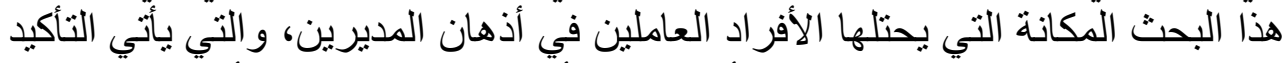

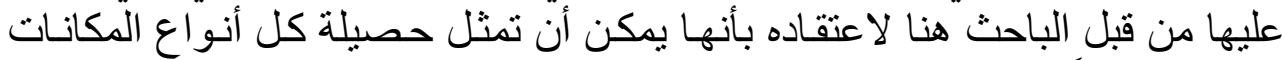

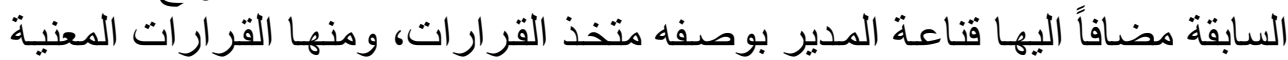
بتحديد مو اقع ودرجات احتر ام الافر اد في منظماتهاتهر.

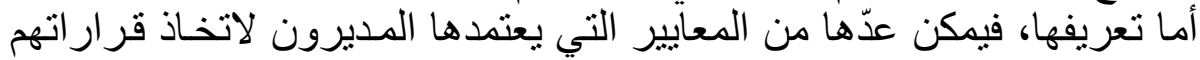

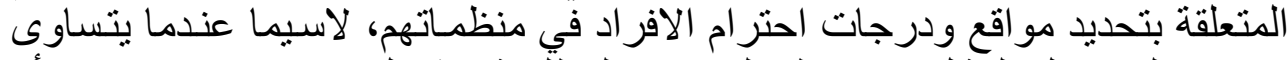

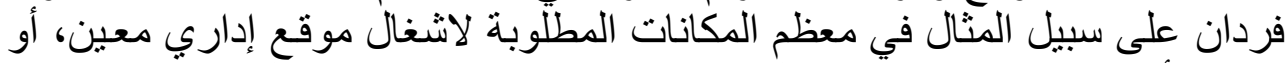

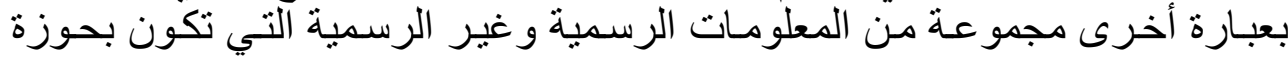

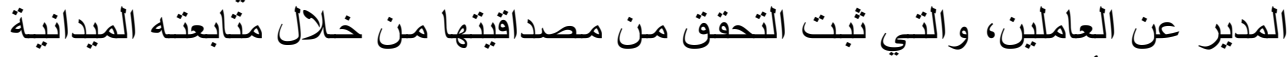

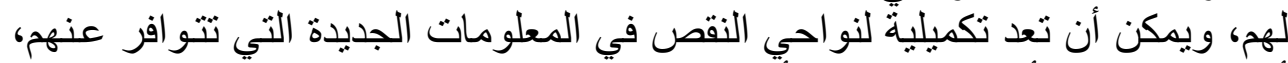

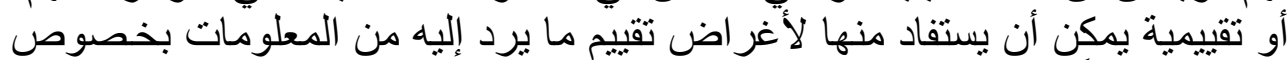

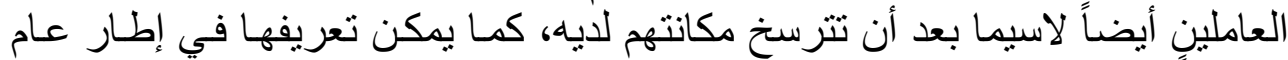

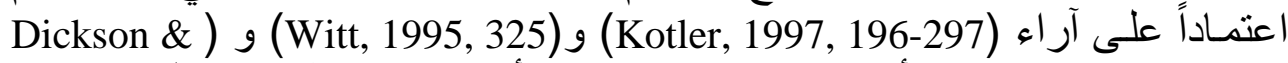
بأنها مجمو عة مدركات و أحاسيس و انطباعـات المدير تجـاه (Games, 1987, 1-10

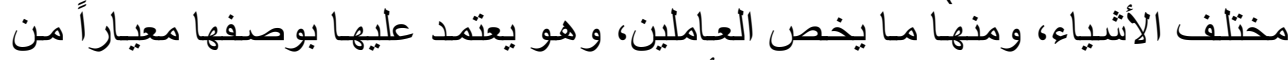

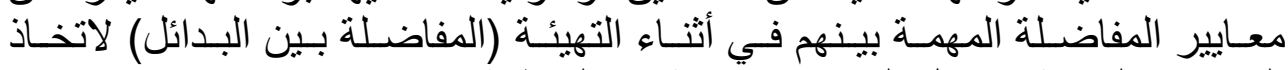

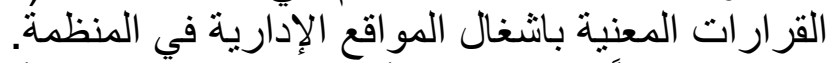

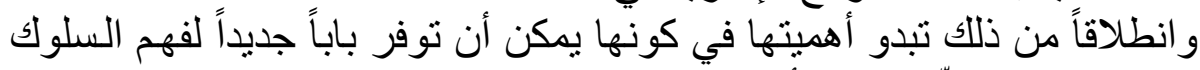

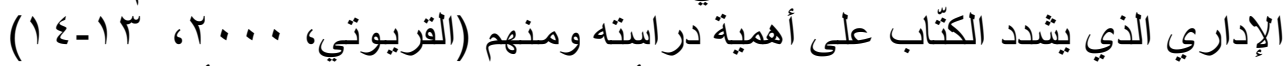

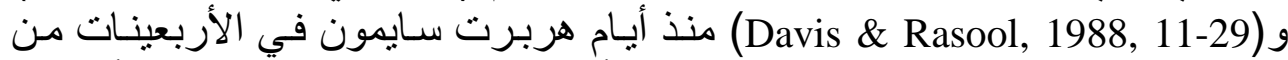

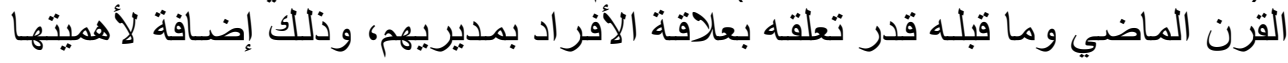

* لمزيد من التفاصيل حول المكانـة الذهنية كما وردت في الأطر النظريـة لإدارة التسويق انظر:

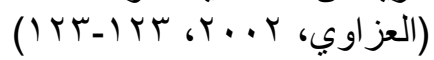




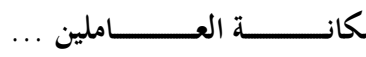

مك-

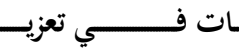

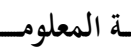

ففافية أنظم

[r०q]

التي سبقت الاشارة إليها في مجالي معالجة نو احي النقص في المعلومات التي تتو افر

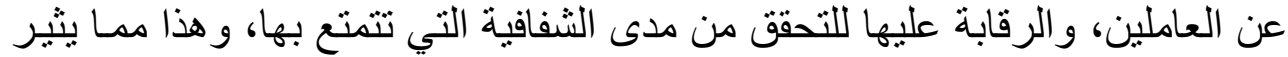

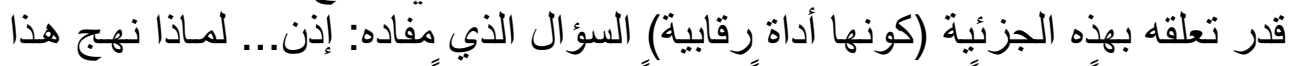

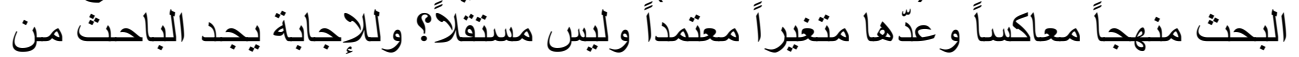

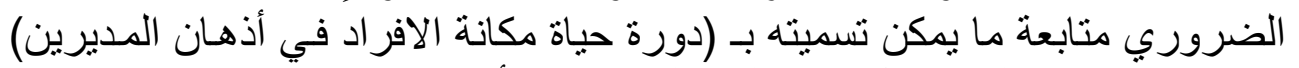

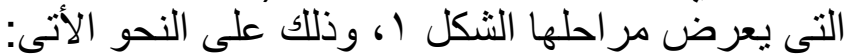

$$
\begin{aligned}
& \text { 1. مرحلة النشأة النا }
\end{aligned}
$$

ويبدأ التأسيس لمكانة الفرد في ذهن مديره في هذه المرحلة، عندما يباثر عمله المانه

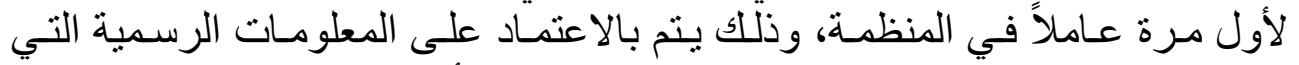

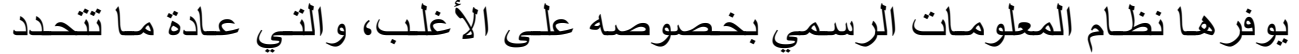

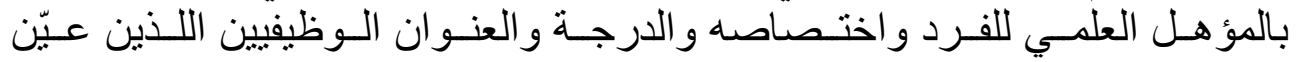

وتبدأ مكانة الفرد في ذهن مديره باللنمو شيئاً فثيئًا، وذللك بالاعتمـاد على ثلاثنة

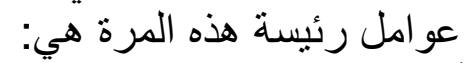

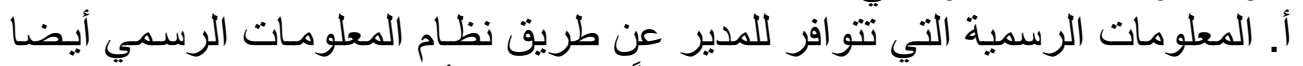

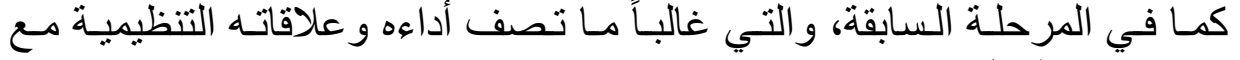

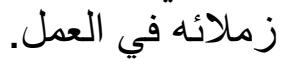

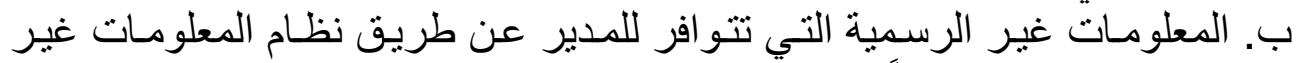

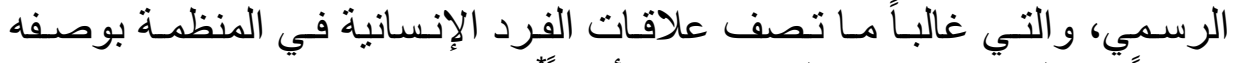

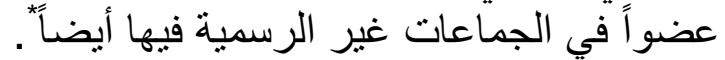
ت. المعلومات الأخرى (الرسمية وغير الرسمية) التي تتجمع لدى الرئية المدير عن الفرد

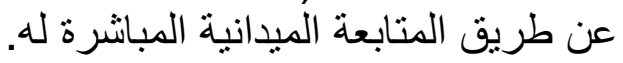

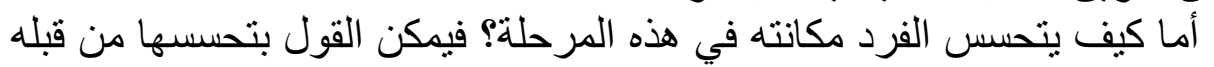

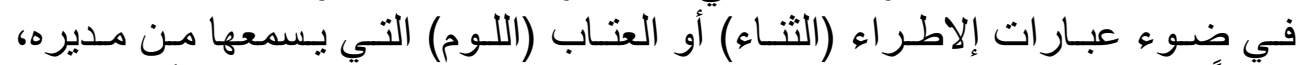

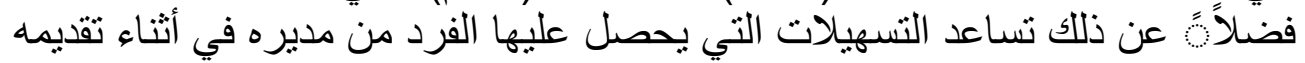

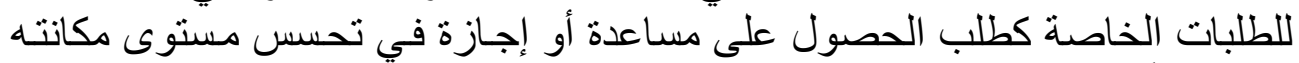
لديه أيضاً.

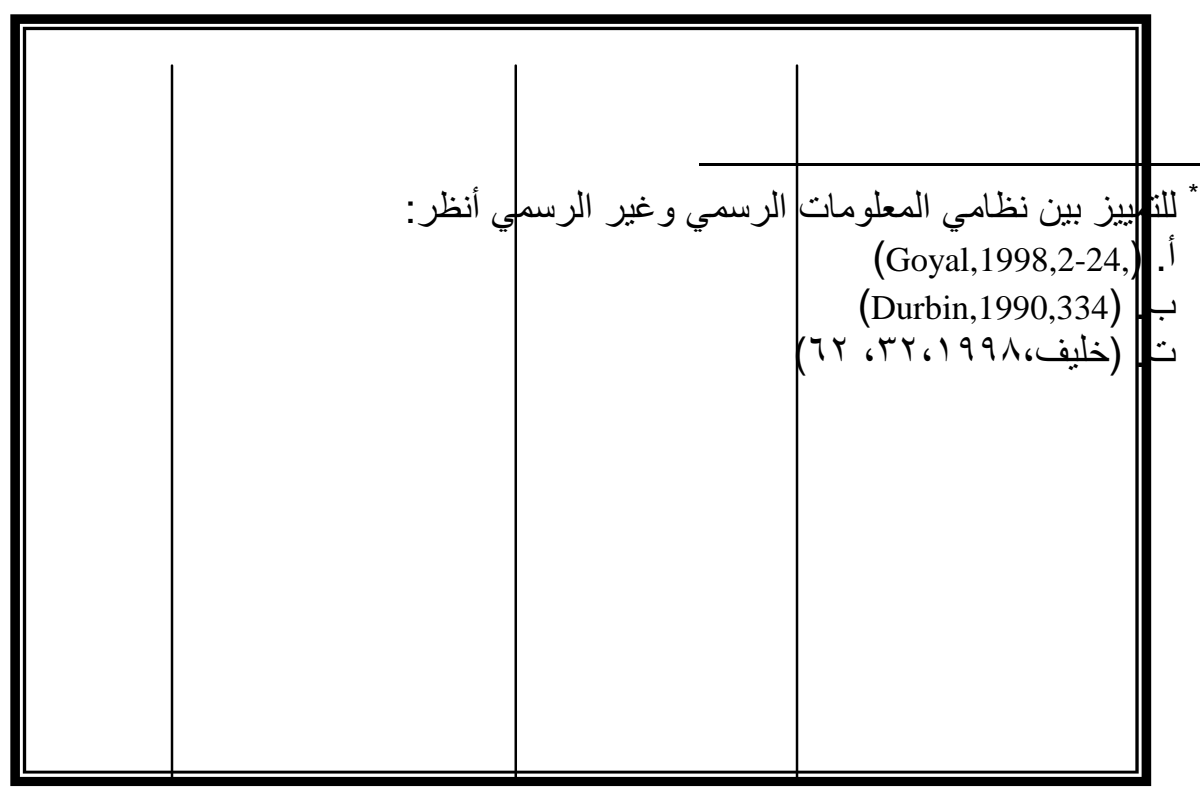




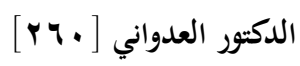

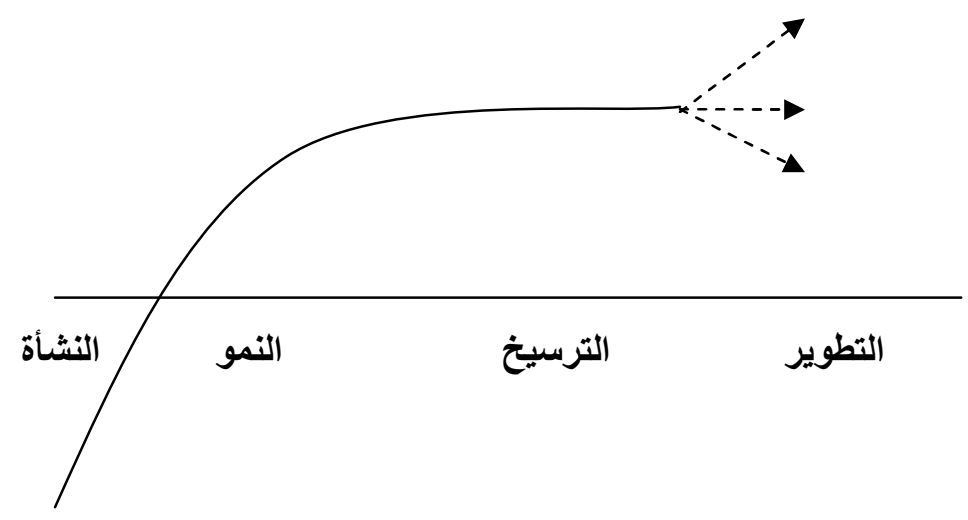

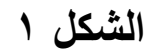

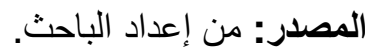

مراحل دورة مكانة الأفراد في أذهان المديرين

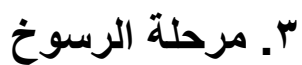

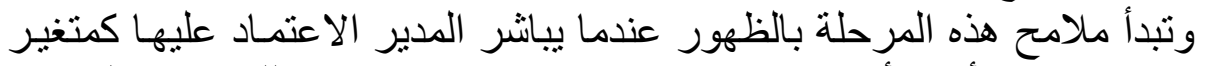

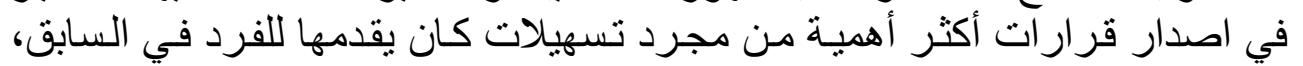

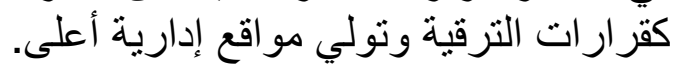

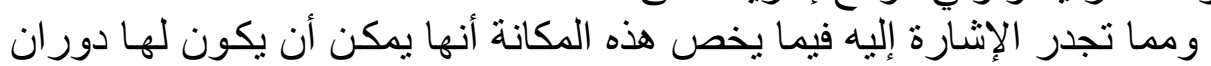

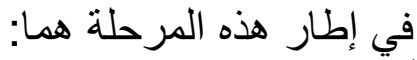

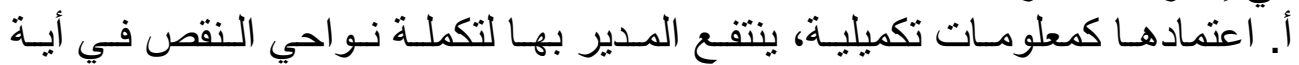

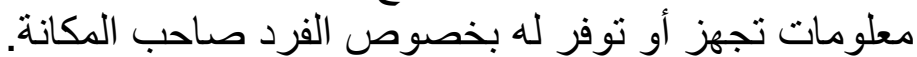

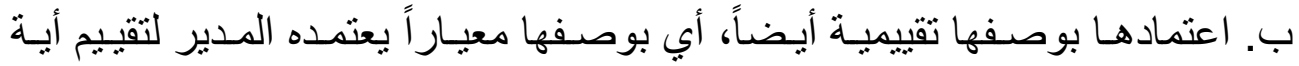
معلومات جديدة تصل إليه بخصوص الفئه الفرد المقصود.

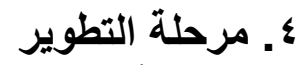

وتبدأ ملامسح هذه المرحلة بـالظهور عندما يفصح المدير المير عن موقفه التقييمي

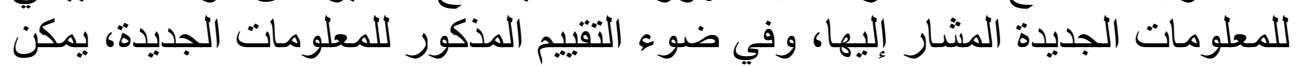

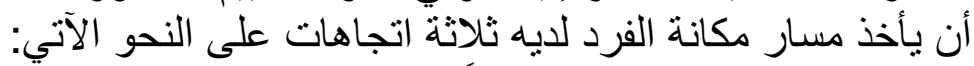

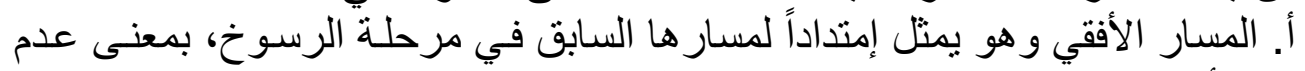

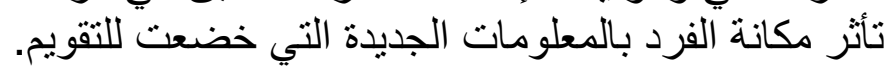




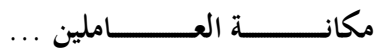<smiles>[14CH3][V]</smiles>
ف

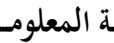

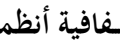

ب. المسار التصاعدي، وذلك عندما تسهم المعلومات الجديدة في تأكيد دقة المعلومات

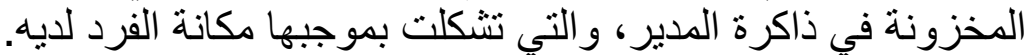

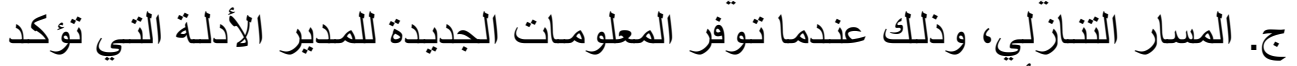

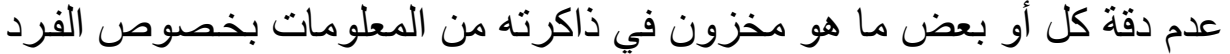
المعني.

\section{الإطار الميداني \\ أولاًا- وصف العينة العينة}

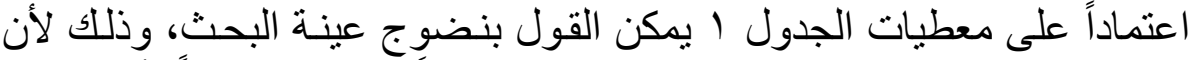

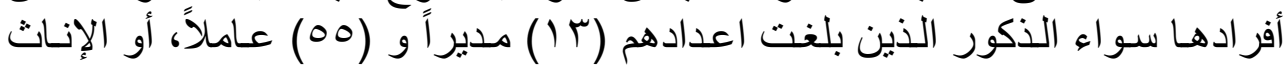

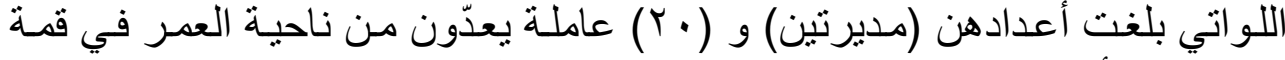

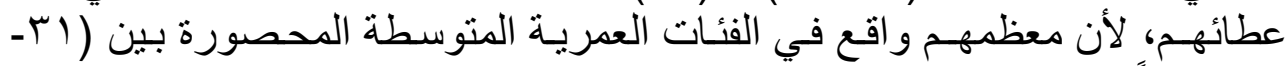
• (0) عاماً مع بعض الاسنثناءات.

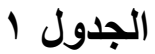

أوصاف عينة البحث

\begin{tabular}{|c|c|c|c|c|c|c|}
\hline \multicolumn{2}{|c|}{ العاملون } & \multicolumn{2}{|c|}{ المديرون } & \multirow{2}{*}{ تصنيفات اللمبمات } & \multirow{2}{*}{ السمات الثخصية } & \multirow{2}{*}{$ت$} \\
\hline النسبة & العدد & النسبة & العدد & & & \\
\hline$\frac{V T}{V T}$ & 00 & $\overline{\lambda V}$ & $\pi$ & ذكور & \multirow{2}{*}{ الجنس } & \multirow{2}{*}{1} \\
\hline$T V$ & $r$. & $T$ & $\bar{T}$ & إناث & & \\
\hline$r$ & $r$ & - & - & r r-r & \multirow{4}{*}{ العمر } & \multirow{4}{*}{ r } \\
\hline$r q$ & rq & - & - & 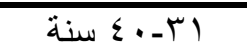 & & \\
\hline or & $\varepsilon \cdot$ & $T V$ & 1. & إ-.0.0 سنة & & \\
\hline 0 & $\varepsilon$ & $\overline{r r}$ & 0 & أكثر من ·مسنة & & \\
\hline 0 & $\varepsilon$ & - & - & • ا سنة فأقل & \multirow{4}{*}{ سنو ات الخدمة } & \multirow{4}{*}{ r } \\
\hline rq & $T V$ & $\pi$ & $r$ & |r.-11 & & \\
\hline 01 & $\varepsilon r$ & 7. & 9 & r r-r.r & & \\
\hline 1 & 1 & rV & $\varepsilon$ & أكثر من · ب سنة & & \\
\hline 10 & 11 & - & - & دبلوم فني & \multirow{5}{*}{ المؤهل العلمي } & \multirow{5}{*}{$\varepsilon$} \\
\hline 01 & $r \Lambda$ & T. & $\bar{r}$ & بكالوريوس & & \\
\hline$T$ & $T$ & $\bar{v}$ & 1 & دبلوم عالي & & \\
\hline rq & TY & 7. & 9 & ماجستير & & \\
\hline$\varepsilon$ & $r$ & 14 & $r$ & دكتور اه & & \\
\hline 0 & $\varepsilon$ & $\mathrm{v}$ & 1 & دورة واحدة & الدورات & 0 \\
\hline
\end{tabular}




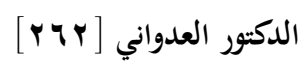

\begin{tabular}{|c|c|c|c|c|c|c|}
\hline \multicolumn{2}{|c|}{ العاملون } & \multicolumn{2}{|c|}{ المديرون } & \multirow{2}{*}{ تصنيفات السمات } & \multirow{4}{*}{ السمات الثخصية } & \\
\hline النسبة & 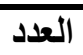 & النسبة & 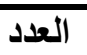 & & & \\
\hline 70 & $\sum 9$ & $\pi$ & $\bar{r}$ & دورتان & & \\
\hline$r$. & $\overline{Y r}$ & A. & $\overline{T r}$ & أكثر من دورتين & & \\
\hline
\end{tabular}

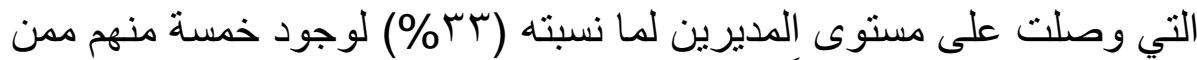

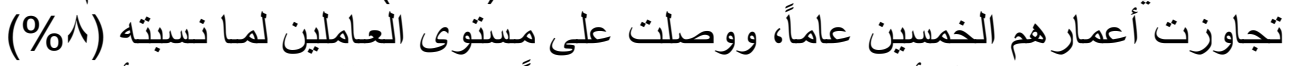

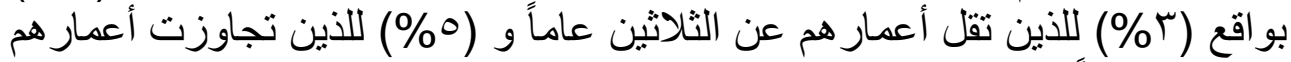

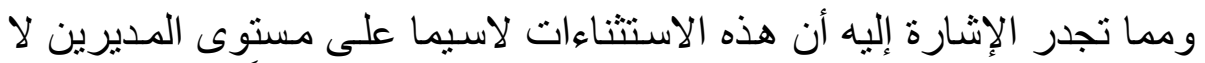

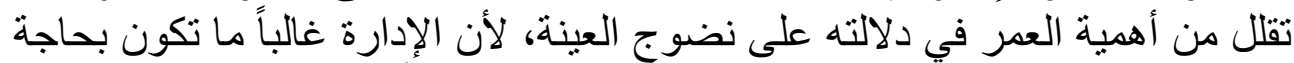

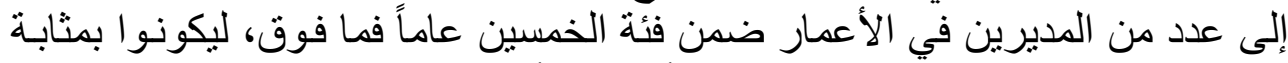
الاليل الذي يسترشد به المديرون ذوي الاعير فين الأعمار الأقل.

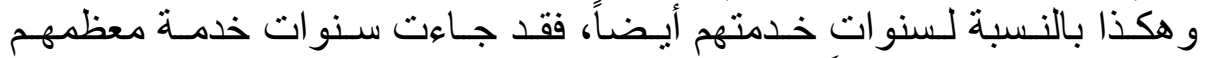

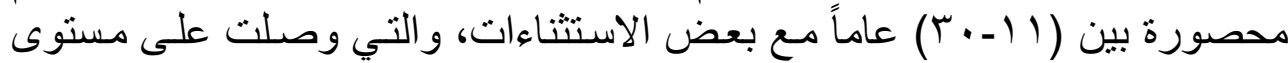

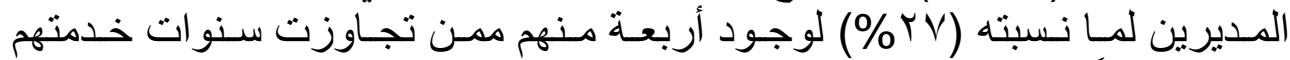

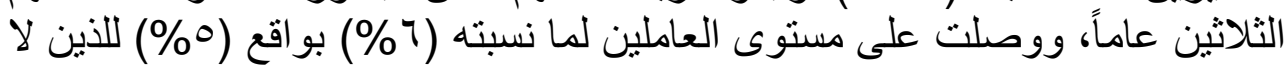

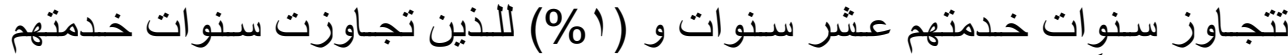

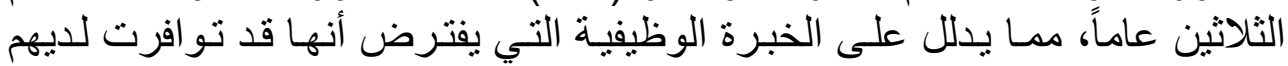

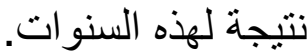

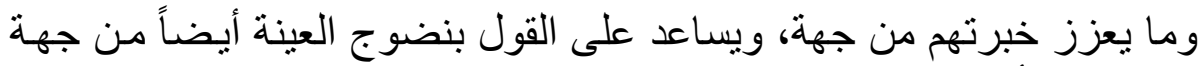

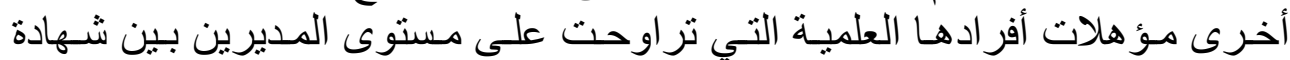

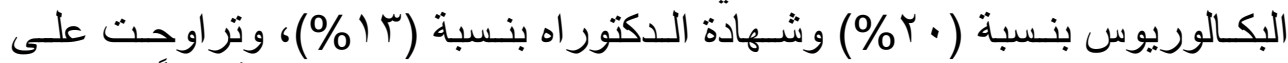

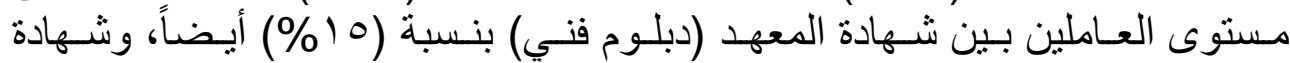

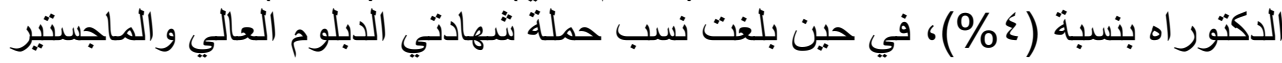

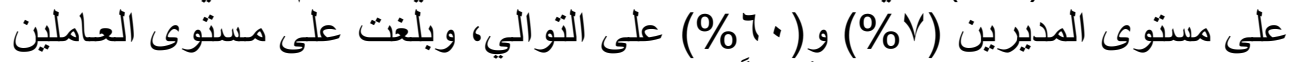

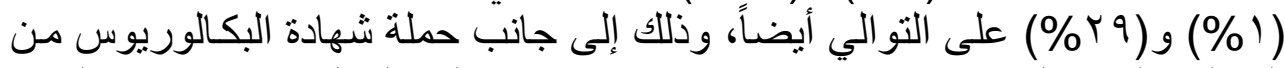

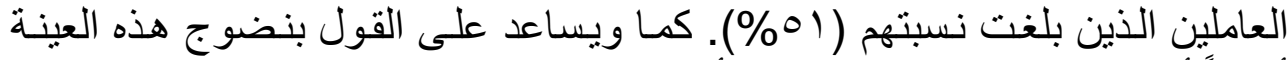

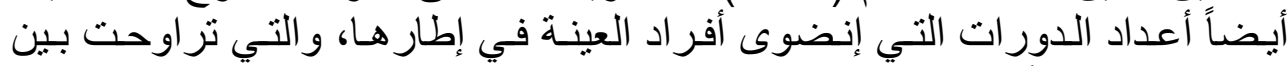

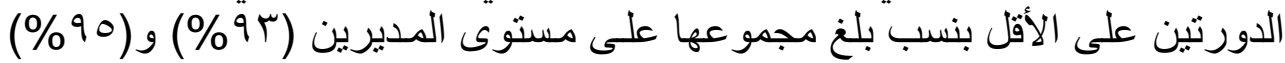

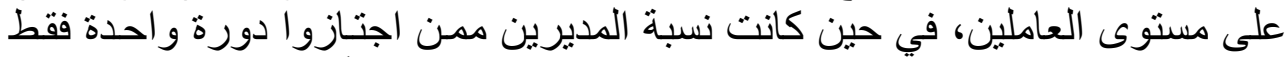

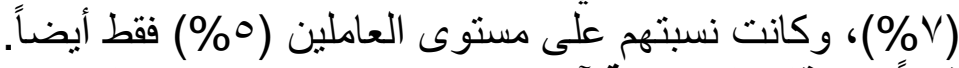

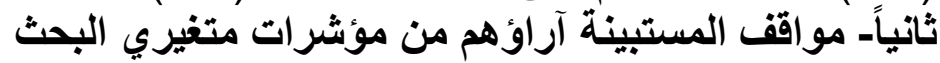

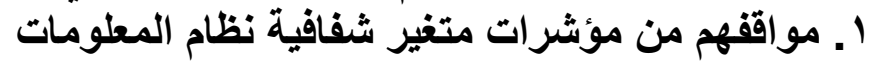

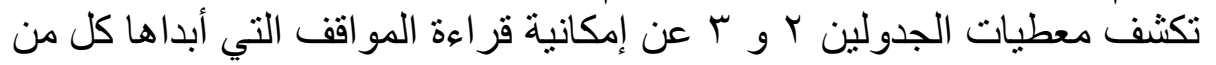
المديرين و العاملين تجاه مؤشرات هذا المتغير من منظورين: 


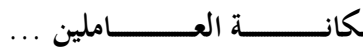<smiles>[Li]</smiles>

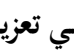

ف

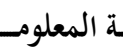

فافية أنظم

الأول: يعكس رضاً عاماً من قبلهما عن مجمل مؤشر ات هذا المتغير ، وذلك بدلالـة

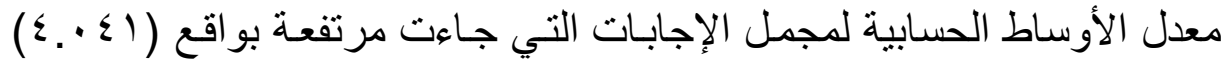

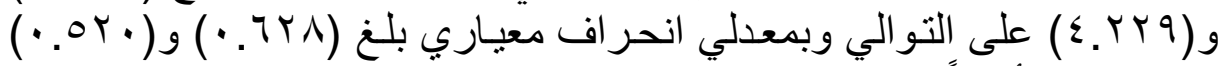
على التو الي أيضاً.

الثاني: يكثف عن نوعين من التباين في المواقف تجاه هذه المؤشر ات ات (تباين قوي

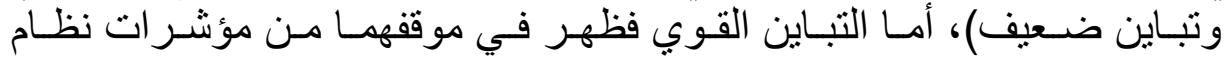

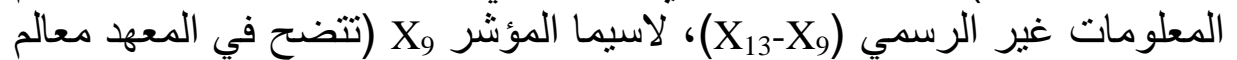

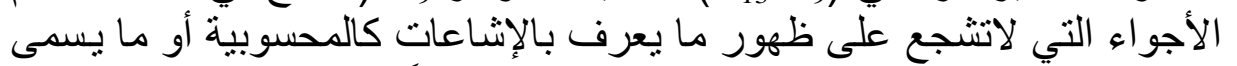

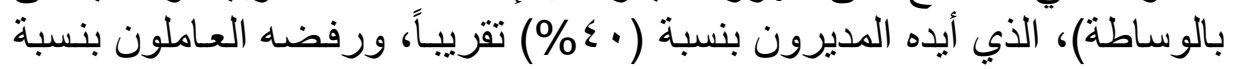
.(\% \%

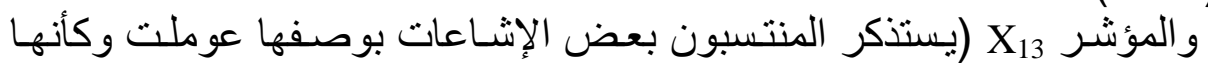

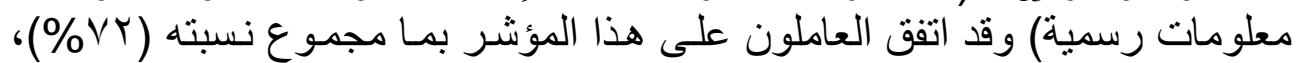
ورفضه المديرون بما مجموع نسبته (.. (1\%) .

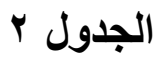

مواقف المديرين من مؤشرات شفافية نظام المعلومات

\begin{tabular}{|c|c|c|c|c|c|c|c|c|c|c|c|c|}
\hline \multirow[t]{2}{*}{ الالانحراف } & \multirow[t]{2}{*}{ الحسابي } & \multicolumn{2}{|c|}{ لا لا اتفقّ } & \multicolumn{2}{|c|}{ لا اتفق } & \multicolumn{2}{|c|}{ محايد } & \multicolumn{2}{|c|}{ اتفق } & \multicolumn{2}{|c|}{ اتثقة } & \multirow{2}{*}{ كلتياس الاستجابة } \\
\hline & & $\%$ & 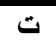 & $\%$ & 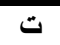 & $\%$ & $ت$ & $\%$ & $\Xi$ & $\%$ & $ت$ & \\
\hline. .201 & E.TV & & & & & v & 1 & $\Lambda$. & IT & $1 \pi$ & $r$ & $\mathrm{X} 1$ \\
\hline .071 & $\varepsilon . Y_{\ldots}$ & & & & & v & 1 & 77 & 1. & $T V$ & $\varepsilon$ & $\mathrm{X} 2$ \\
\hline$\cdot . Y Y \varepsilon$ & E.TrT & & & & & $1 \pi$ & $r$ & $\varepsilon$. & 7 & $\varepsilon V$ & $\mathrm{~V}$ & $\mathrm{X3}$ \\
\hline (.£) & $\varepsilon . \wedge \ldots$ & & & & & - & - & $r$. & $r$ & $\Lambda$. & IT & $\mathrm{X} 4$ \\
\hline $.7 \leqslant \cdot$ & $\varepsilon .0 T r$ & & & & & v & 1 & $\pi$ & 0 & 7. & 9 & $\mathrm{X5}$ \\
\hline$\therefore V \mu V$ & ะ.7.. & & & & & $1 \pi$ & $r$ & $1 \pi$ & $r$ & $V \varepsilon$ & 11 & X6 \\
\hline$\because V \cdot \varepsilon$ & E.YTV & & & & & $1 \pi$ & $r$ & $\leqslant V$ & $\mathrm{v}$ & $\varepsilon \cdot$ & 7 & $\mathrm{X} 7$ \\
\hline .1999 & E.TV & & & & & $T V$ & $\varepsilon$ & $\varepsilon$. & 7 & rT & 0 & X8 \\
\hline$\therefore$ VVO & $r . r_{\mu}$ & & & $\bar{r}$. & $r$ & $\varepsilon$. & 7 & $\varepsilon$. & 7 & - & - & X9 \\
\hline$\therefore .107$ & $\varepsilon \ldots$ & & & & & $T V$ & $\varepsilon$ & $\varepsilon 7$ & $\mathrm{~V}$ & TV & $\varepsilon$ & $\mathrm{X10}$ \\
\hline$\cdot . T K r$ & $\varepsilon .7 \ldots$ & & & & & $\mathrm{V}$ & 1 & $T V$ & $\varepsilon$ & 74 & 1. & $\mathrm{X11}$ \\
\hline $.0 . \mathrm{V}$ & ะ.7.. & & & & & & & $\varepsilon$ & 7 & 7. & 9 & X12 \\
\hline$\because .201$ & 1. ITV & $V T$ & 11 & rV & $\varepsilon$ & & & & & & & X13 \\
\hline$\cdot .7 Y \wedge$ & 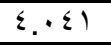 & V & 1 & $r$ & .0 & $1 \pi$ & $r$ & $r v$ & 0.0 & $\varepsilon \cdot$ & 7 & الإجمالي \\
\hline
\end{tabular}

المصدر: من إعداد الباحث في ضوء الحهاسبة الالكترونية.

ويمكن أن تعزى مو اقف المديرين إلى المسؤولية التي يتحملونها في إدارة

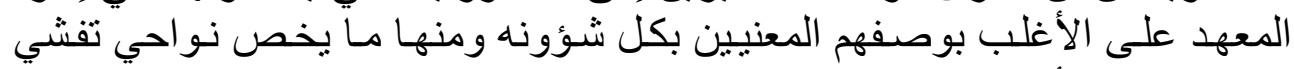

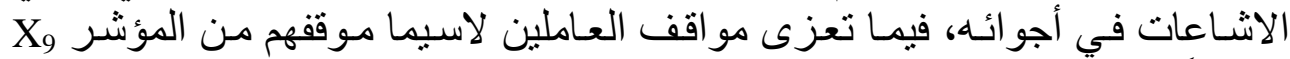

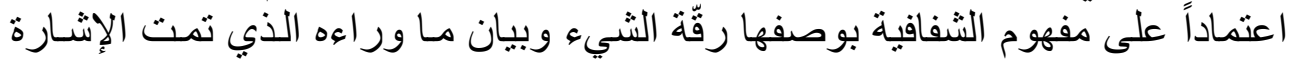


إليه في الإطار النظري، و الذي ربما يقصده العاملون أو لا يقصدونه في سعيهم نحو البهو

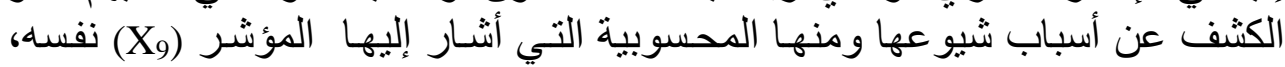

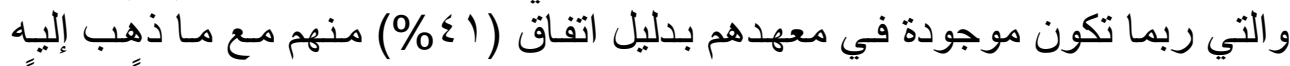

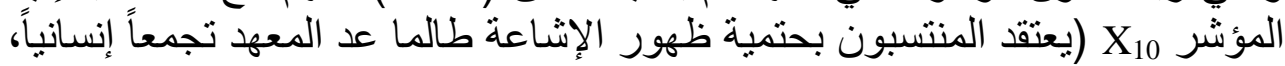

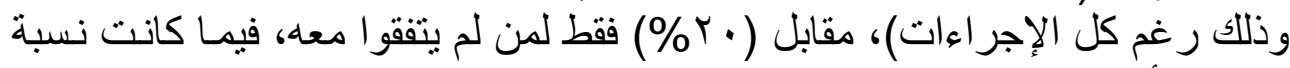

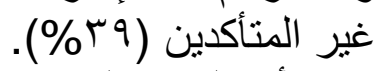
أما التباين الضعيف فظهر في في الموقف من مؤشر ات نظام المعلومـات الرسمي (X $\left.\mathrm{X}_{8}-\mathrm{X}_{1}\right)$

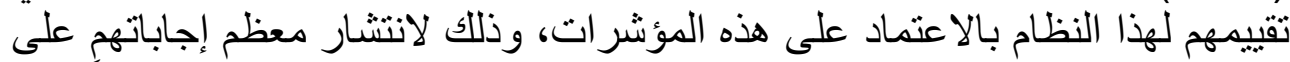

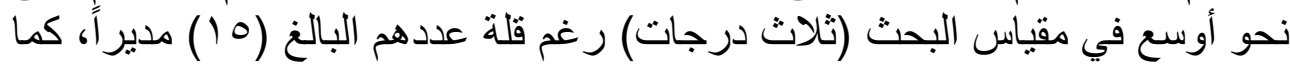

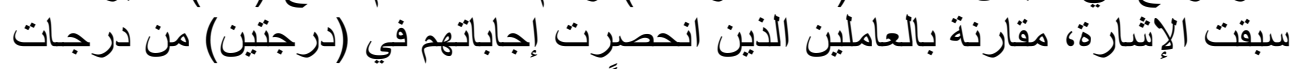

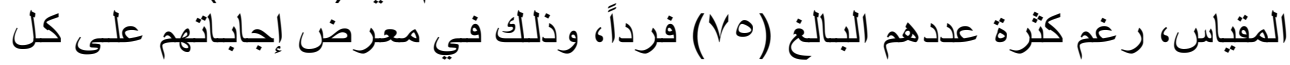

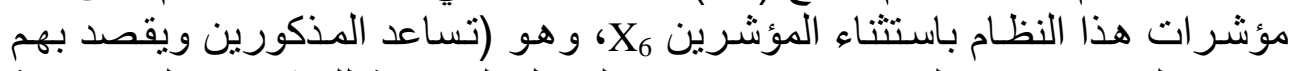

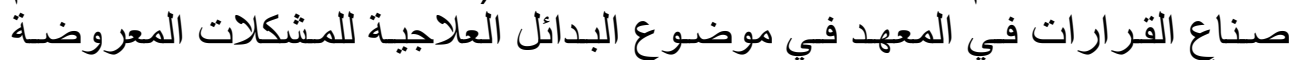

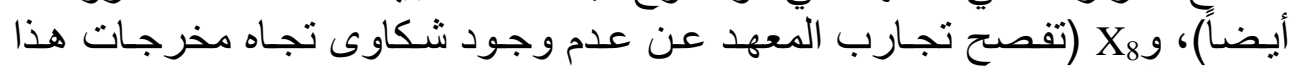

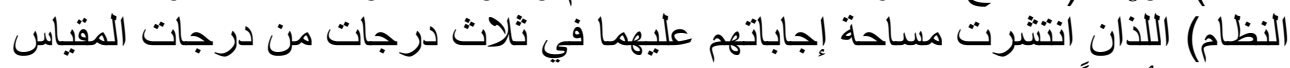
الدذكور أيضاً.

ويمكن من جهة أخرى أن يوفر التباين الذي ظهر بين وجهتي نظر المديرين

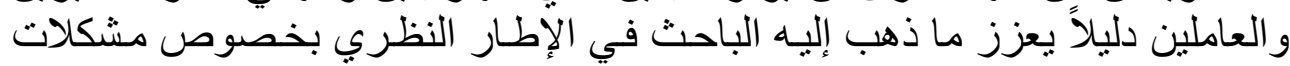

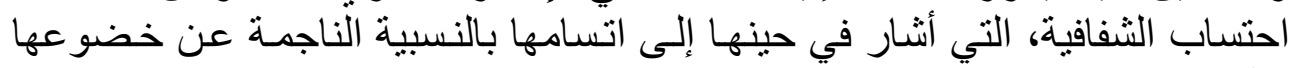

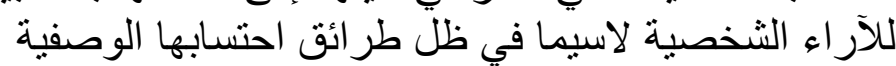

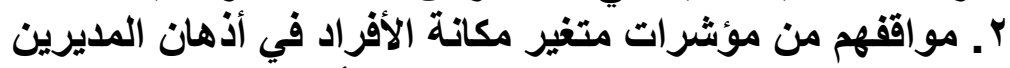

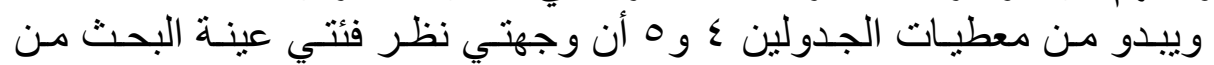

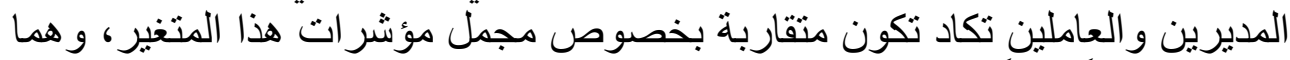

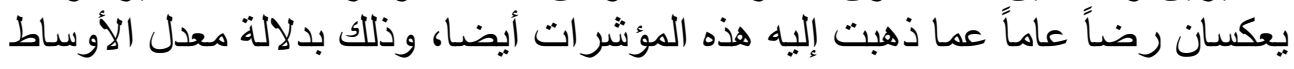

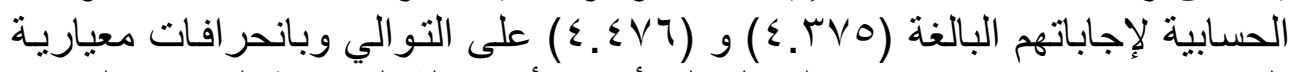

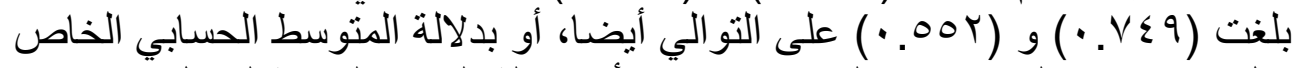

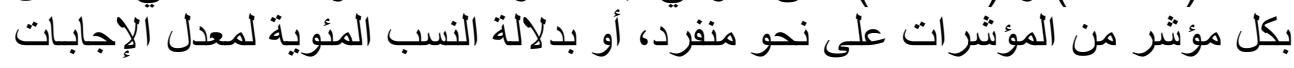

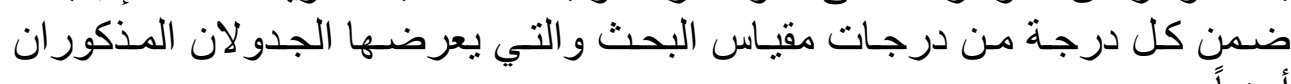

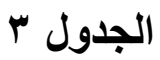

مواقف العاملين من مؤشرات شفافية نظام المطلومات

\begin{tabular}{|c|c|c|c|c|c|c|c|c|c|c|c|c|}
\hline \multirow[t]{2}{*}{ المعياري } & \multirow[t]{2}{*}{ الحسابي } & \multicolumn{2}{|c|}{ لا اتفقة } & \multicolumn{2}{|c|}{ لا اتفق } & \multicolumn{2}{|c|}{ محايد } & \multicolumn{2}{|c|}{ اتفق } & \multicolumn{2}{|c|}{ بثدة اتفق } & \\
\hline & & $\%$ & $ت$ & $\%$ & $ت$ & $\%$ & $ت$ & $\%$ & $ت$ & $\%$ & ت & \\
\hline
\end{tabular}




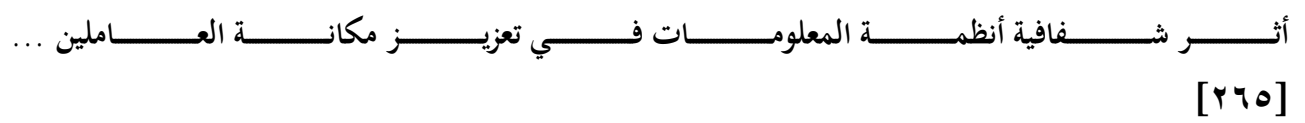

\begin{tabular}{|c|c|c|c|c|c|c|c|c|c|c|c|c|}
\hline$\because \leqslant 01$ & $4 . \mathrm{V} \cdot \mathrm{V}$ & & & & & & & rq & Tr & vi & or & $\mathrm{X} 1$ \\
\hline$\theta \leqslant 01$ & $\varepsilon . V \cdot V$ & & & & & & & rq & Tr & $\overline{v 1}$ & Or & $\mathrm{X} 2$ \\
\hline$\because \leqslant 91$ & $\varepsilon .0 V T$ & & & & & & & $\varepsilon r$ & Tr & or & $\varepsilon r$ & $\mathrm{X3}$ \\
\hline$\theta \leqslant r$. & $\varepsilon . \vee 7$. & & & & & & & $T \xi$ & 11 & $V 7$ & OV & $\mathrm{X} 4$ \\
\hline$\theta \varepsilon \cdot \Gamma$ & $\varepsilon . \wedge \ldots$ & & & & & & & $r$. & 10 & $\lambda_{.}$ & 7. & $\mathrm{X5}$ \\
\hline$\because .091$ & $\varepsilon .07$. & & & & & 0 & $\varepsilon$ & $r \mu$ & To & 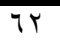 & $\leqslant 7$ & X6 \\
\hline$\theta \leqslant \pi \wedge$ & $\varepsilon . V \leqslant V$ & & & & & & & To & 19 & vo & 07 & X7 \\
\hline. $.0 Y A$ & \&.TV & & & & & 11 & $\Lambda$ & $V Y$ & $0 \xi$ & IV & $1 \pi$ & $\mathrm{X8}$ \\
\hline $.0 \% \pi$ & $1 . r \leqslant v$ & 71 & 01 & rq & $T Y$ & $r$ & $\bar{r}$ & & & & & X9 \\
\hline - & r.rA. & & & $r$. & 10 & $r q$ & rq & $r \varepsilon$ & rq & $\bar{v}$ & 0 & $\mathrm{X10}$ \\
\hline$\cdot . \leqslant 94$ & 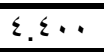 & & & & & & & 7. & $\leqslant 0$ & $\varepsilon$ & $r \cdot$ & X11 \\
\hline 0.101 & $\varepsilon .9 \pi r$ & & & & & & & v & 0 & 94 & $v \cdot$ & X12 \\
\hline$\cdot \wedge \cdot \wedge$ & $\varepsilon .94$ & & & & & YA & $r$ & $\Gamma \varepsilon$ & YT & $r \Lambda$ & YA & X13 \\
\hline. $.0 Y$. & $\varepsilon . r 4 q$ & 0 & $\varepsilon$ & $\varepsilon$ & $r$ & $\mathrm{v}$ & 0 & $r \mu$ & $T \varepsilon$ & OY & $r q$ & الإجمالي \\
\hline
\end{tabular}

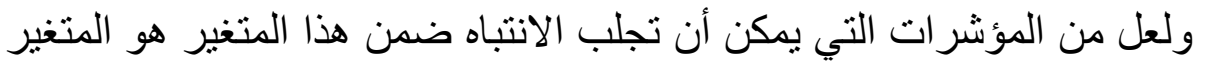

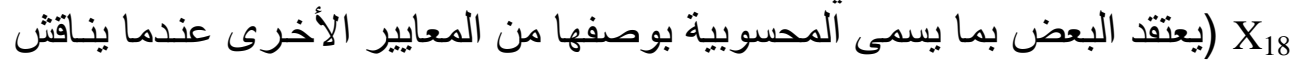

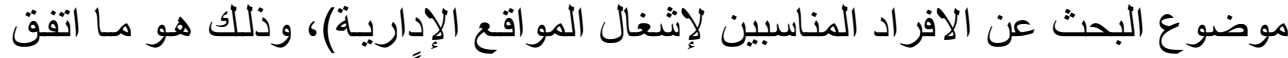

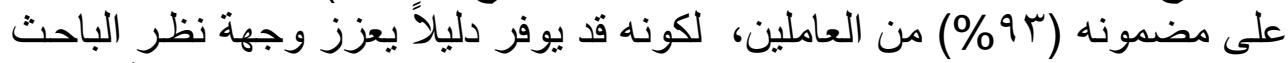

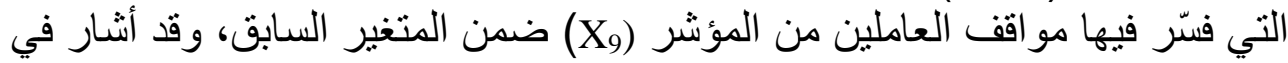

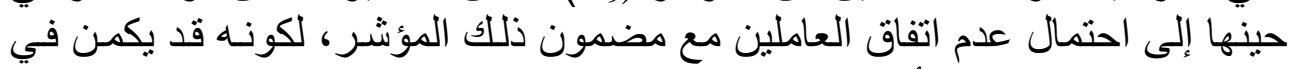

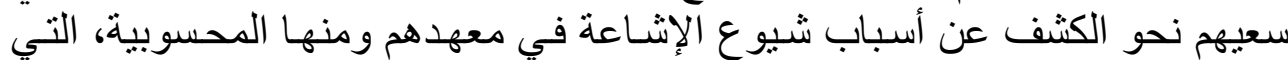

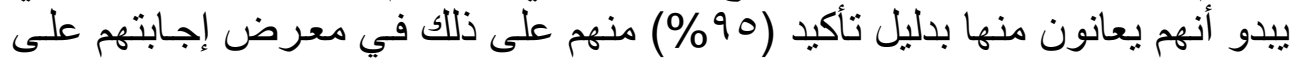

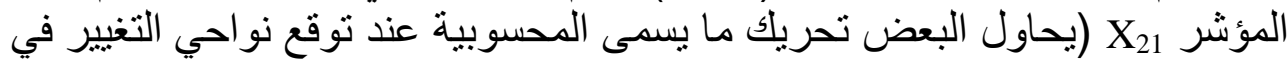
المو اقع الإدارية للمعهد).

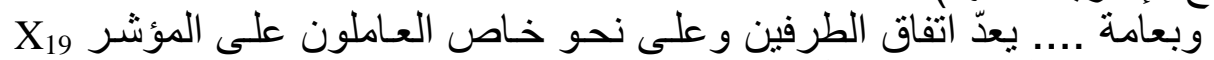

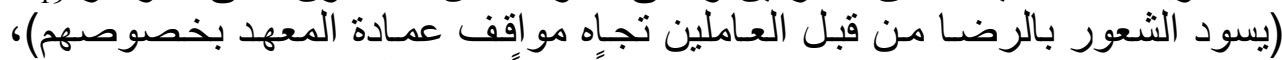

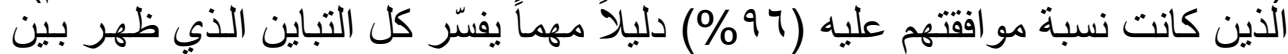

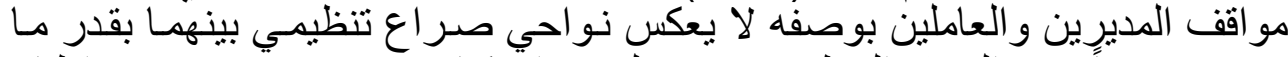

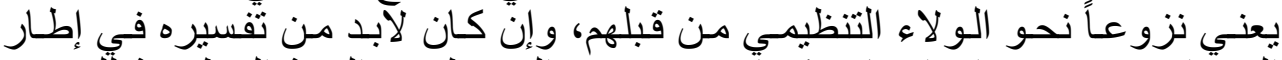

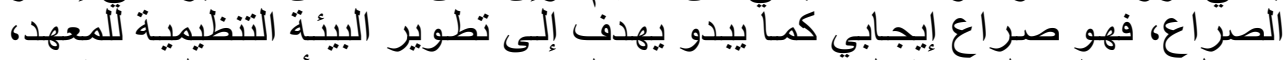

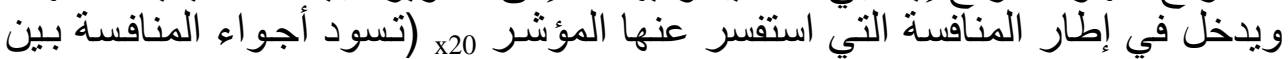

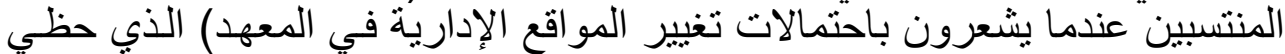

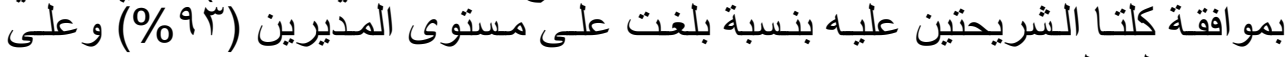
مستوى العاملين (90\%) (90).

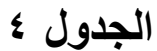

مواقف المديرين من مؤشرات مكانة الأفراد في أذهان المديرين 


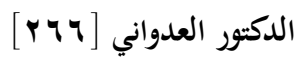

\begin{tabular}{|c|c|c|c|c|c|c|c|c|c|c|c|c|}
\hline \multirow[t]{2}{*}{ الالحرياري } & \multirow[t]{2}{*}{ الحسابي } & \multicolumn{2}{|c|}{ لا لا اتفق } & \multicolumn{2}{|c|}{ لا اتفق } & \multicolumn{2}{|c|}{ محايد } & \multicolumn{2}{|c|}{ اتفق } & \multicolumn{2}{|c|}{ اتفق بشدة } & \multirow{2}{*}{ كقياس الاستجابة } \\
\hline & & $\%$ & ت & $\%$ & $ت$ & $\%$ & $ت$ & $\%$ & $ت$ & $\%$ & $ت$ & \\
\hline$\because 7 \varepsilon$. & $\varepsilon .0 T r$ & & & & & $\bar{V}$ & 1 & r & 0 & 7. & 9 & X14 \\
\hline$\because 7 \varepsilon$. & $\varepsilon . \leqslant 7 V$ & & & & & $V$ & 1 & $\varepsilon$. & 7 & or & $\Lambda$ & X15 \\
\hline$\because \leqslant 0 \wedge$ & $\varepsilon . V T r$ & & & & & & & TV & $\varepsilon$ & $V T$ & 11 & X16 \\
\hline . & $\varepsilon . \varepsilon \ldots$ & & & & & $\mathrm{V}$ & $T$ & $\sum 7.0$ & $V$ & $\{7.0$ & $V$ & $\mathbf{X 1 7}$ \\
\hline$\because V \leqslant r$ & r.ATV & & & & & $\overline{T r}$ & 0 & $\varepsilon V$ & $\bar{v}$ & $r$. & $r$ & X18 \\
\hline .071 & $\Sigma . \wedge \ldots$ & & & & & $\bar{V}$ & 1 & $\bar{v}$ & 1 & $\overline{\Lambda T}$ & $1 \pi$ & X19 \\
\hline .071 & 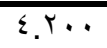 & & & & & $\bar{V}$ & 1 & 77 & 1. & $T V$ & $\varepsilon$ & $\mathrm{X} 20$ \\
\hline$\cdot . r \vee \wedge$ & $\varepsilon \ldots$ & & & & & $V$ & $T$ & $\lambda \bar{T}$ & $1 \pi$ & $\bar{V}$ & 1 & X21 \\
\hline$\because v \leqslant q$ & $\varepsilon . r v o$ & & & & & $V$ & 1 & $\sum 7.0$ & $V$ & $\{7.0$ & $V$ & الإجمالي \\
\hline
\end{tabular}

المصدر: من إعداد الباحث في ضوء الحاسبة الالكترونية

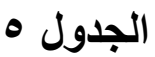

مواقف العاملين من مؤشرات مكانة الأفراد في أذهان المديرين

\begin{tabular}{|c|c|c|c|c|c|c|c|c|c|c|c|c|}
\hline \multirow{2}{*}{ الاتحراف } & \multirow{2}{*}{ الحسابي الوسط } & \multicolumn{2}{|c|}{ لا اتفقة } & \multicolumn{2}{|c|}{ لا اتفق } & \multicolumn{2}{|c|}{ محايد } & \multicolumn{2}{|c|}{ اتفق } & \multicolumn{2}{|c|}{ اتفق بشدة } & \multirow{2}{*}{ المتغيرات مقياس الاستجابة } \\
\hline & & $\%$ & $ت$ & $\%$ & ت & $\%$ & $ت$ & $\%$ & $ت$ & $\%$ & 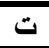 & \\
\hline.$r q r$ & $\Sigma . \wedge 1 \Gamma$ & & & & & & & 19 & $1 \varepsilon$ & 1) & 71 & X14 \\
\hline$\cdot \leq 7 \leq$ & $5.79 \%$ & & & & & & & T & $r T$ & 79 & Or & X15 \\
\hline$\cdot \wedge 1 \mathrm{~V}$ & $\varepsilon .1 \leqslant V$ & & & & & $T V$ & $r$. & $\overline{r r}$ & $T \varepsilon$ & 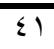 & 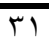 & X16 \\
\hline $.0 . \mathrm{V}$ & $5.70 r$ & & & & & 1 & 1 & $r r$ & $r \xi$ & $7 V$ & 0. & $\mathbf{X 1 7}$ \\
\hline .097 & E.TY. & & & & & $V$ & 0 & 00 & 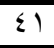 & $r \Lambda$ & rq & X18 \\
\hline. $.0 V Y$ & $\varepsilon .0 \wedge V$ & & & & & $\varepsilon$ & $r$ & rT & ro & $7 \pi$ & $\varepsilon V$ & X19 \\
\hline .7 .1 & $\varepsilon . \leqslant \Lambda$. & & & & & 0 & $\varepsilon$ & $\varepsilon$ & $\pi$ & $0 \leqslant$ & $\varepsilon$. & $\mathrm{X20}$ \\
\hline$\cdot . \leqslant 7 \leqslant$ & $\varepsilon .1 \%$ & & & & & 0 & $\varepsilon$ & $\mathrm{VA}$ & 01 & IV & $1 \pi$ & X21 \\
\hline $.00 Y$ & $\varepsilon . \Sigma \vee\urcorner$ & & & & & $V$ & 0 & $\varepsilon$. & $r$. & Or & $\varepsilon$. & الإجمالي \\
\hline
\end{tabular}

\section{ثالثاً اختبار فرضيات البحث}

1 ـ اختبار علاقة الارتباط بين شفافية نظام المطلومات وبين مكانة الأفراد في أذهان

$$
\text { المديرين }
$$

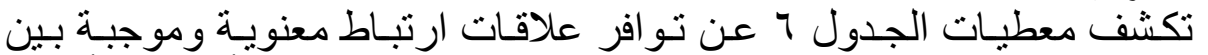

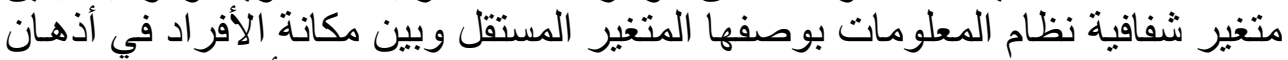

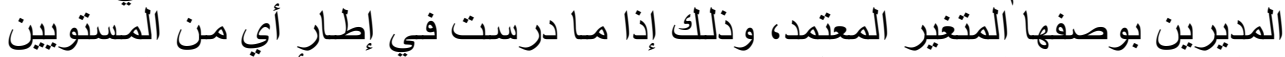

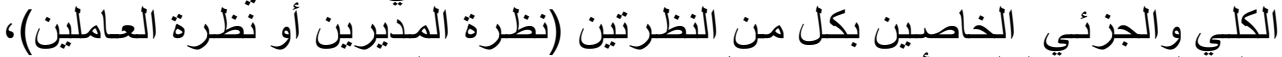

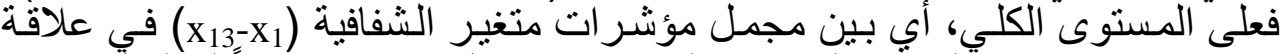

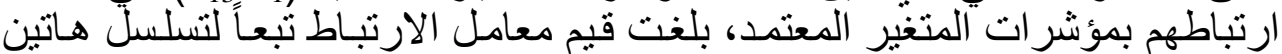

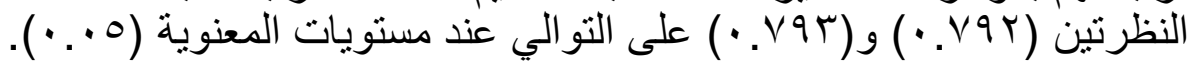




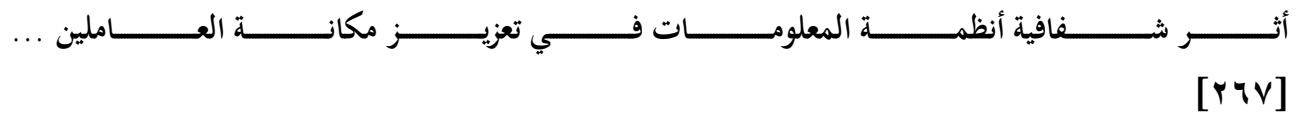

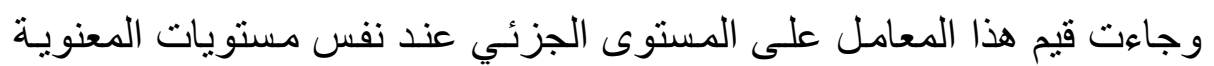

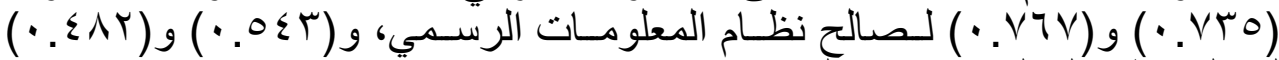

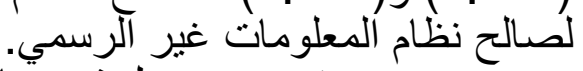

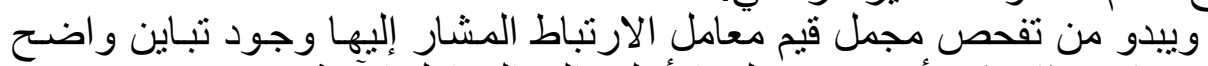

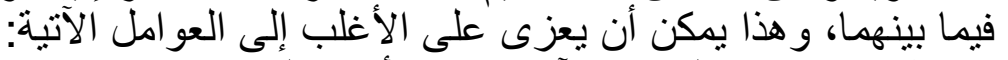

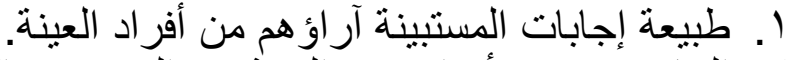

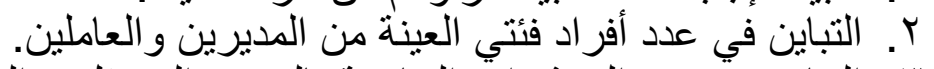

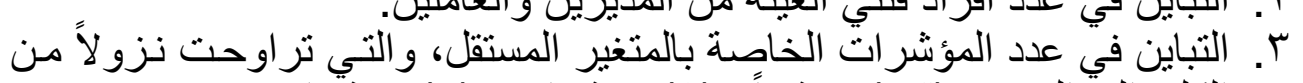

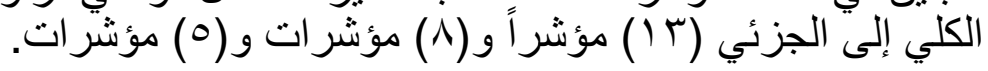

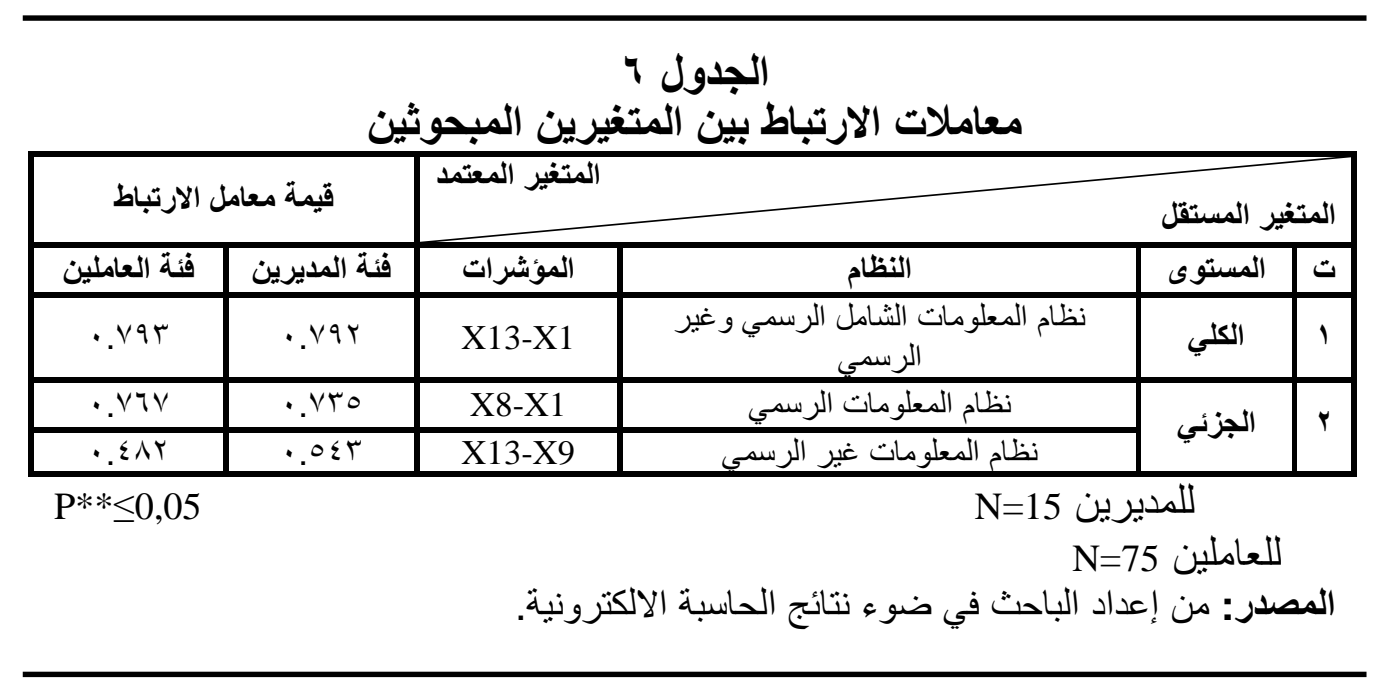

r. اختبـار علاقـة الأثر بـين شفافية نظـام المعلومـات ومكانـة الأفراد في أذهـان المديرين

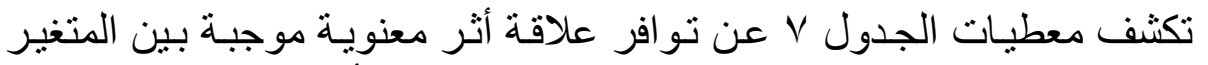

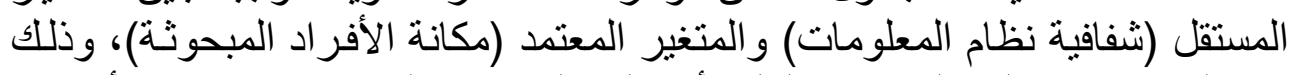

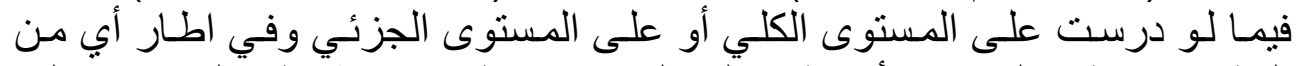

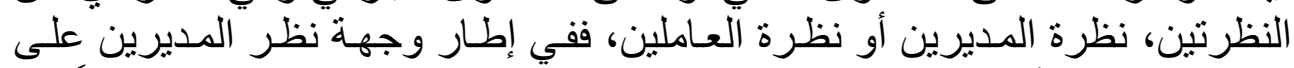

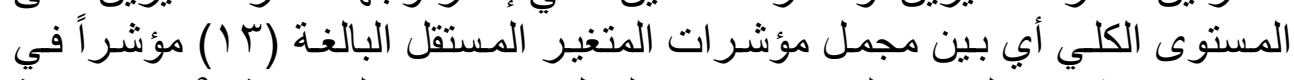

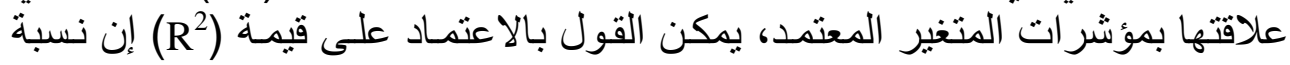

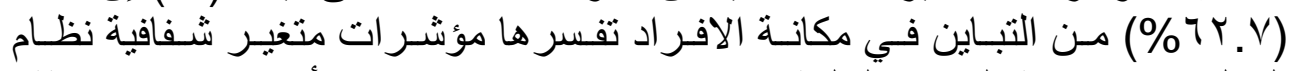

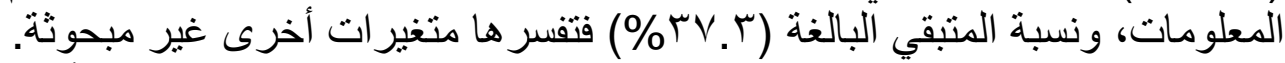

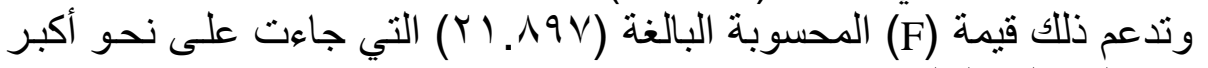

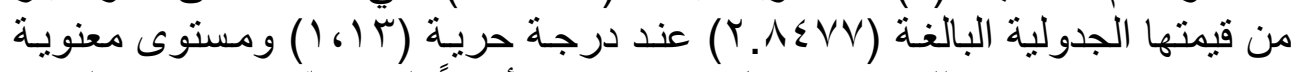

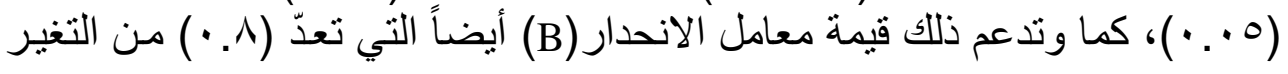




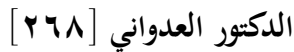

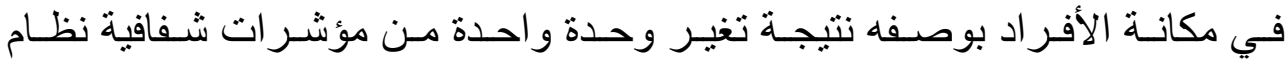

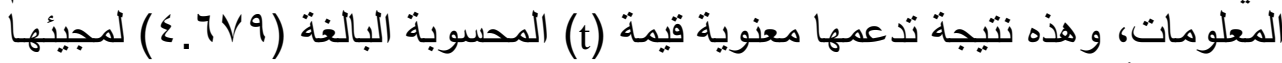

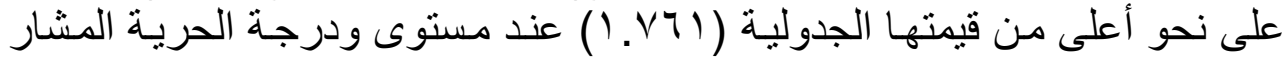
إليهما.

وما ذكر بخصوص ما عبرت عنه وجهة نظر المديرين من علاقة الأثر المشار

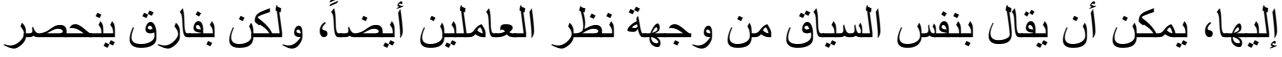

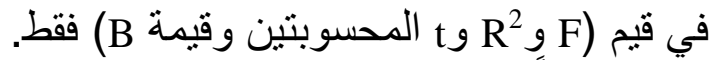

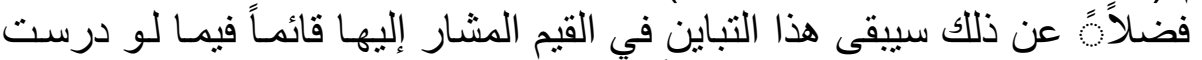

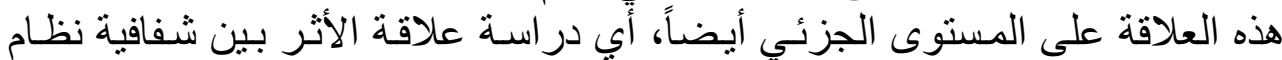

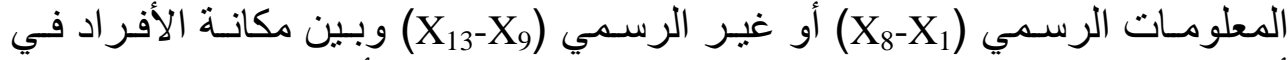

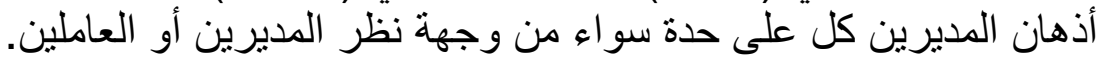

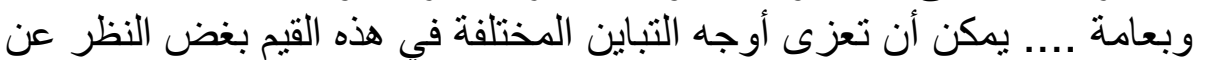
الإستوى أو النظام الذي تدرس فيه لنفس الأسباب التي أدت إلى النى التباين في معاملات الارتباط التي سبقت الإثارة إليها.

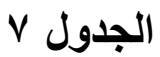

معاملات الأثر بين المتغيرين المبحوثين

\begin{tabular}{|c|c|c|c|c|c|c|c|c|c|}
\hline \multirow{2}{*}{\multicolumn{7}{|c|}{ مكانة الأفراد }} & \multicolumn{3}{|c|}{ المتغير المعتمد } \\
\hline & & & & & & & & & لمتغير المستقل \\
\hline \multicolumn{2}{|c|}{$\mathrm{T}$} & \multirow{2}{*}{$\beta$} & \multicolumn{2}{|c|}{$\bar{F}$} & \multirow{2}{*}{ D.F } & \multirow{2}{*}{$\mathrm{R}^{2}$} & \multirow{2}{*}{ الفئة } & \multirow{2}{*}{ المؤشر ات } & \multirow{2}{*}{ نظام المعلومات | } \\
\hline الجدولية & المحسوبة & & الجدولية & المحسوبة & & & & & \\
\hline 1.871 & $\varepsilon .7 \vee 9$ & $\cdot \wedge$ & 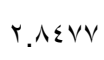 & Y..人9V & ir & $.7 T V$ & المديرون & \multirow{2}{*}{ X13- X1 } & \multirow{2}{*}{ وغير الرسمي) (الرسمي } \\
\hline $1.77 \leqslant 0$ & 11.149 & $\cdot .10$ & r.rrqa & IKT.NTr & 1 & . $.7 \% 9$ & العاملون & & \\
\hline 1.871 & $r . q \cdot v$ & $\cdot 9$ & r.AEVY & $\mid 0.171$ & ir & $.0 \leqslant$. & المديرون & \multirow{2}{*}{$\mathrm{X} 8-\mathrm{X} 1$} & \multirow{2}{*}{ الرسمي } \\
\hline $1.77 \leqslant 0$ & $1 \cdot, K M$ & T & r.rYqI & $1 . \varepsilon . \varepsilon V V$ & $\frac{1}{v}$ & .019 & العاملون & & \\
\hline 1.271 & T.rYq &. $.7 \varepsilon$ & r.AEVY & $\left.0 . \sum Y\right\}$ & 'r & . rqs & المديرون & \multirow{2}{*}{$\mathrm{X} 13-\mathrm{X} 9$} & \multirow{2}{*}{ غير الرسمي } \\
\hline $1.77 \leqslant 0$ & $\sum .797$ & $\cdot .771$ & r.rYqI & Tr. $.0 \varepsilon$ & $\frac{1}{v}$ & • TKY & العاملون & & \\
\hline
\end{tabular}

الاستتتاجات والمقترحات الات المات

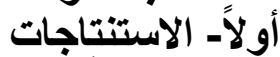

اعتماداً على ما تقام يمكن الخروج بنو عين من الاستنتاجات على النقات النحو الآتي:

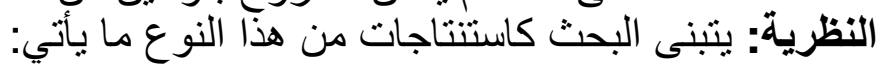




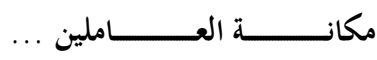

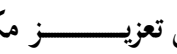

فات

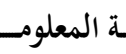

ففافية أنظم

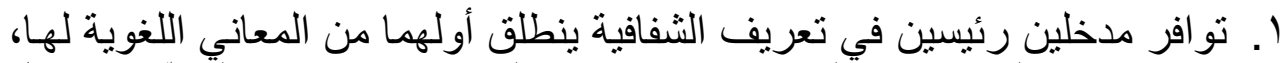

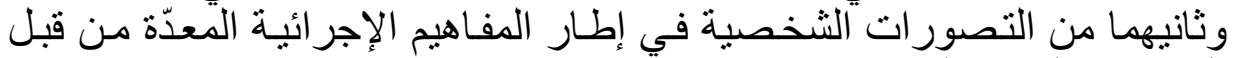

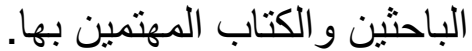

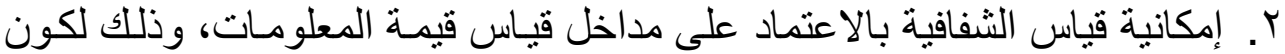

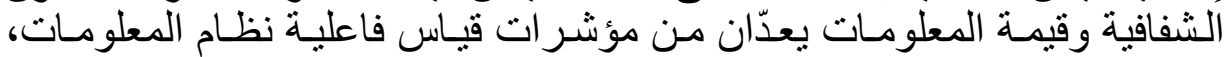

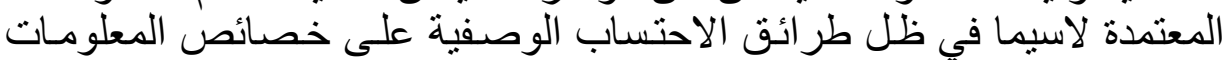

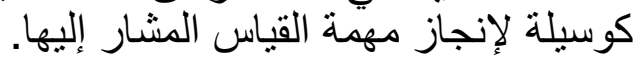

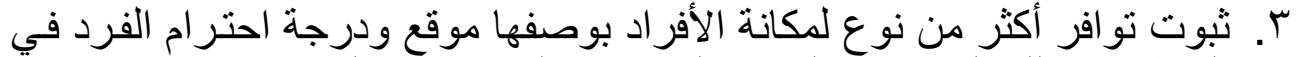

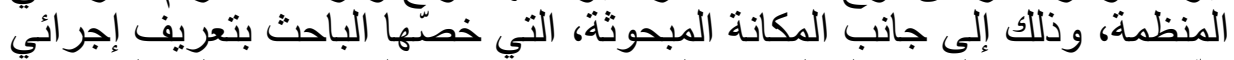

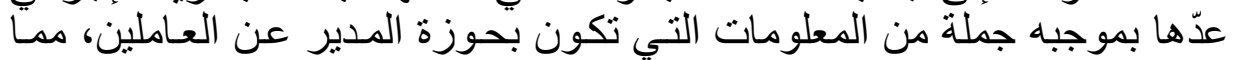

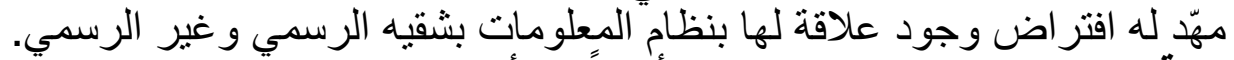

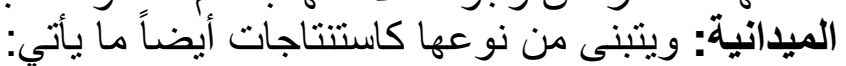

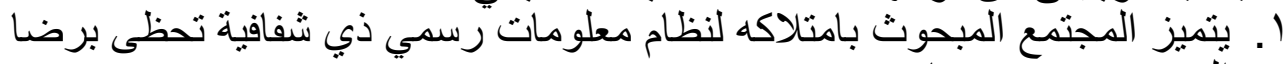
المستفيدين من خدماته.

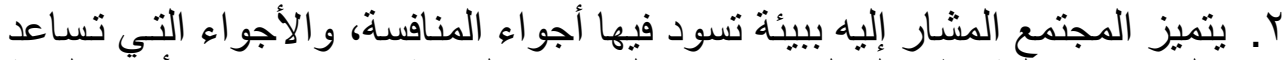

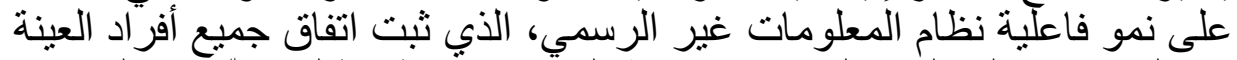

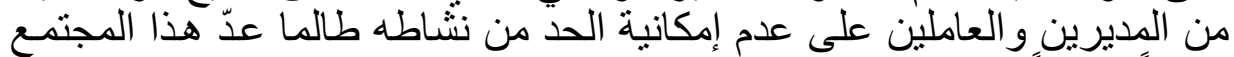
تجمعاً إنسانياً.

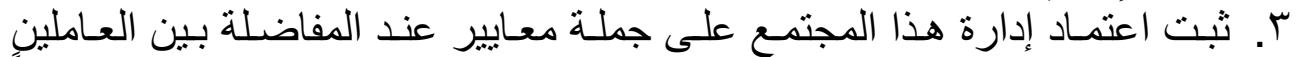

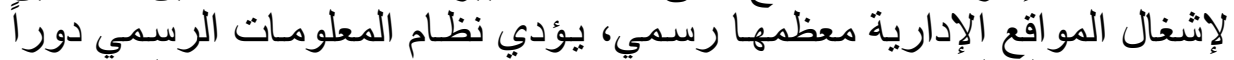

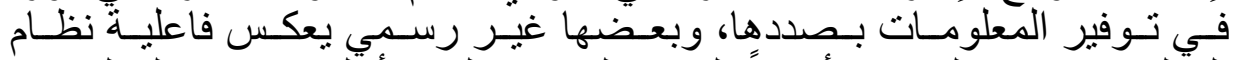

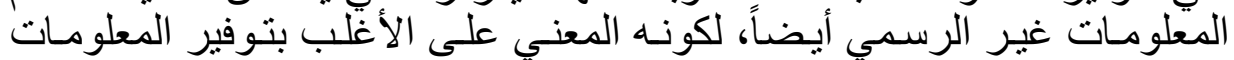
بصددها.

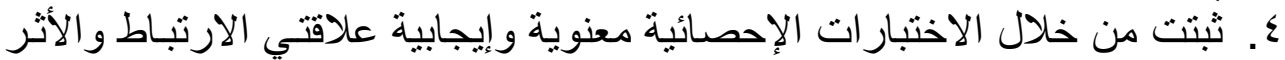

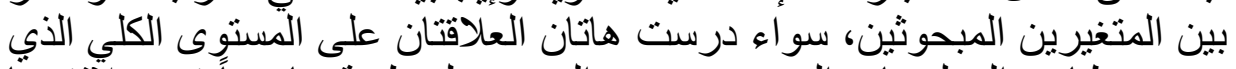

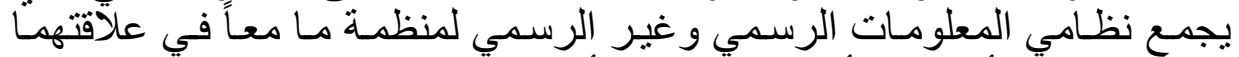

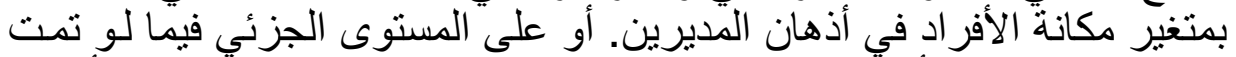

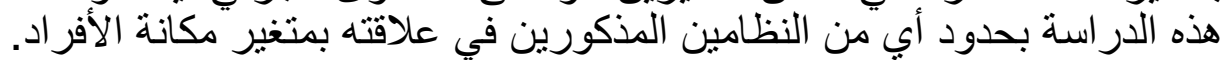

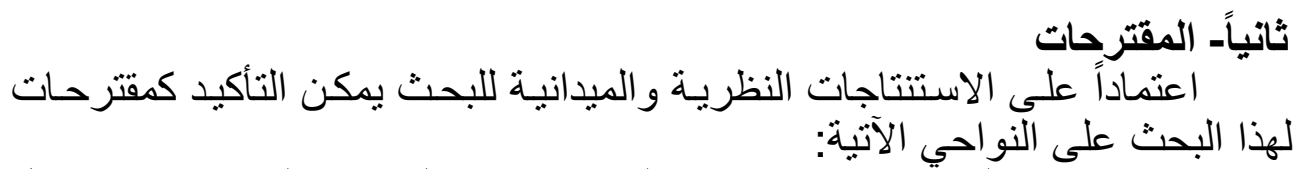

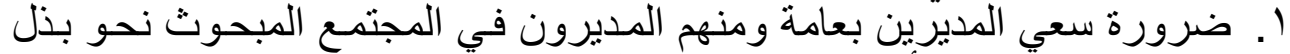

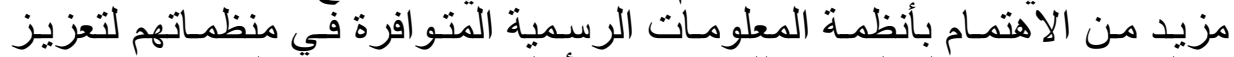

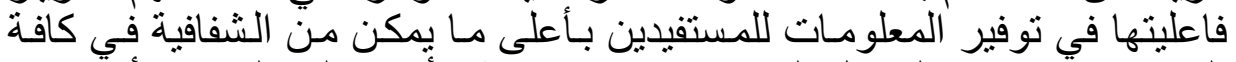

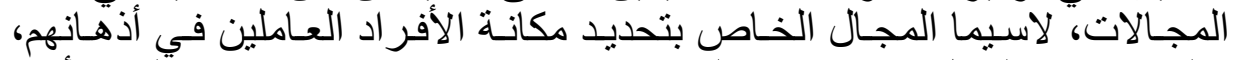

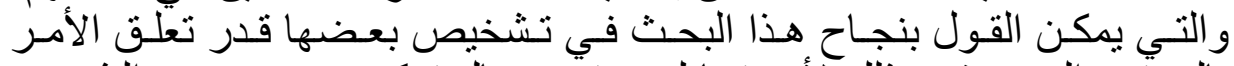

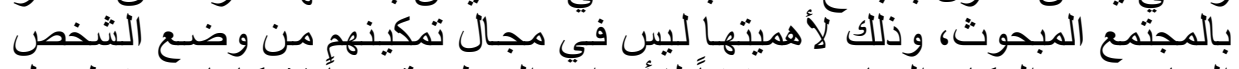

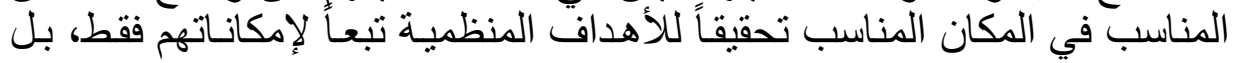




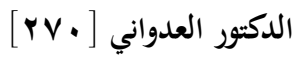

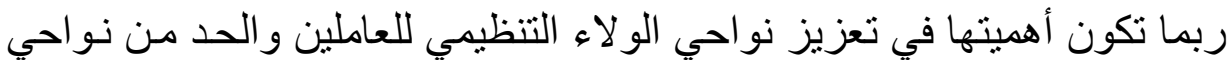

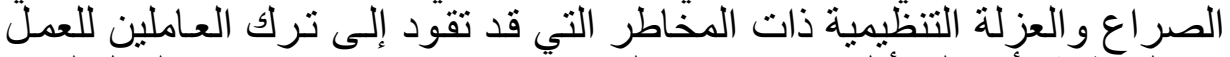

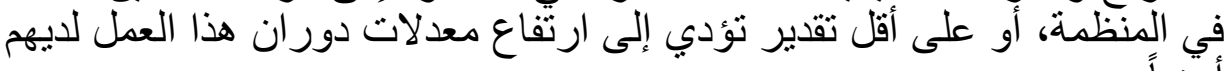

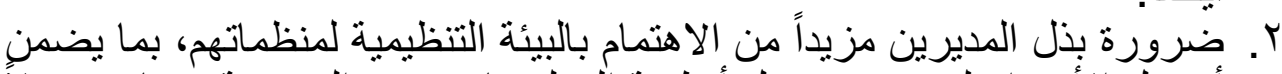

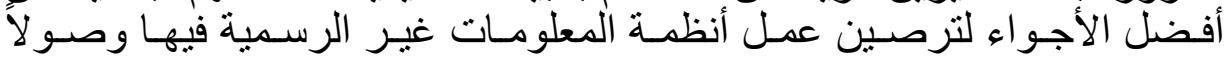

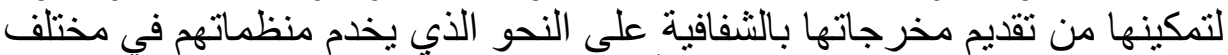
المجالات ومنها مجال تحديد مكانة الأفر اد لديهح.

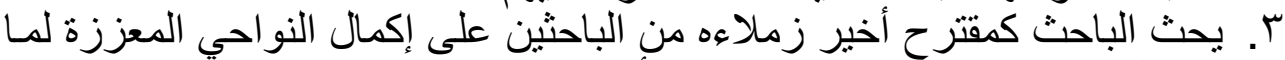

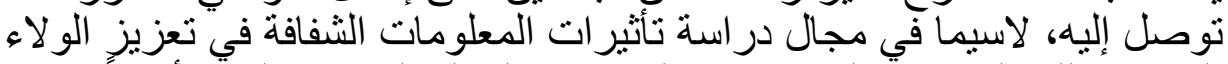

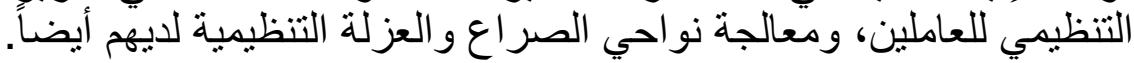

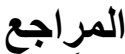 \\ أولاًِ المراجع باللغة العربية}

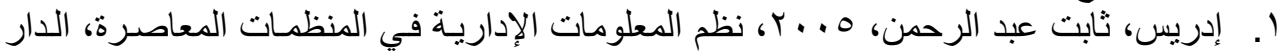

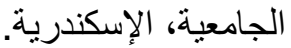

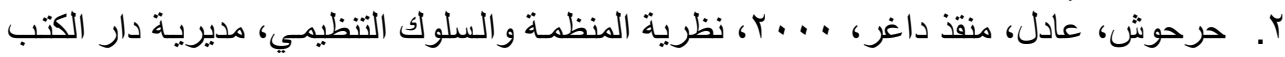

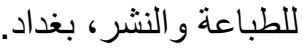

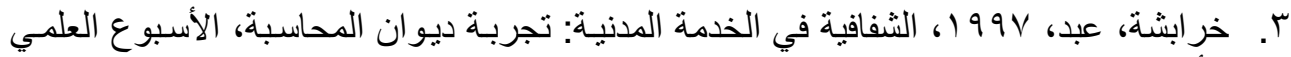

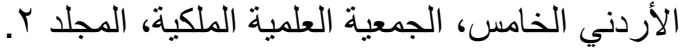

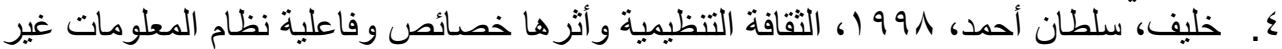

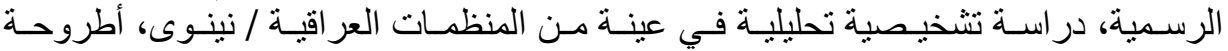

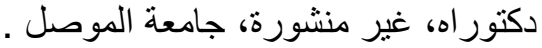
○. الثماع، خليل محمد حسن، 999 (19، مبادئ الإدارة مع التركيز على إدارة الإعمال، دار الكتب

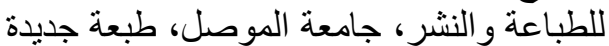

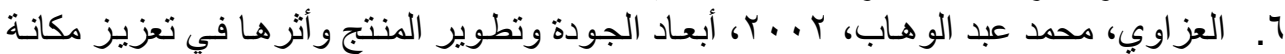

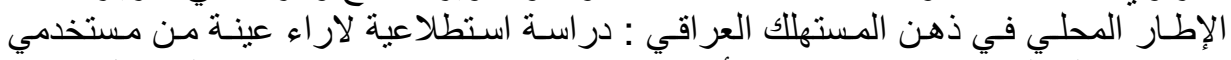

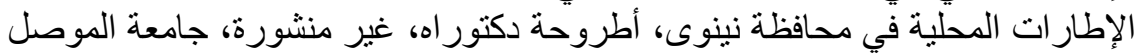

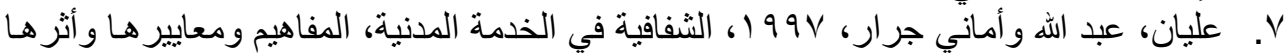
في الخدمة المدنية، ديوان الخدمة الملكية الأردني، الأسبوع العلمي الخـامس، الجمعية العلمية التهية

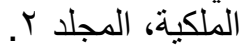

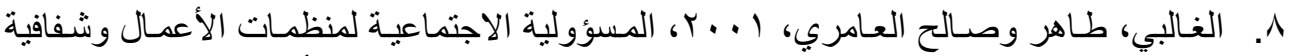

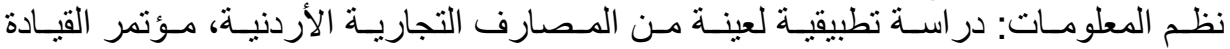

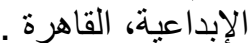

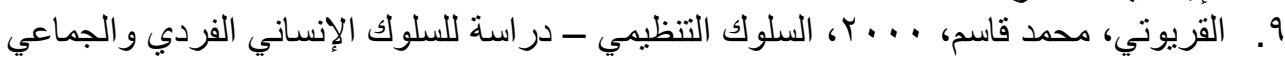
في المنظمات الحديثة، دار الثروق للنشر و التوزيع، عمان.

\section{ثاتياً- المراجع باللغة الأجنبية}

1. B. Ronald, Mitchell, 1998, "Sources Of Transparency Information System In International Regimes, University Of Oregon .

2. Davis, H.J \& Rasool, S.A.1988Values Research \& Managerial Behavior Implications For Devising Culturally Consistent Managerial Styles, Management international Review Vol : 28 


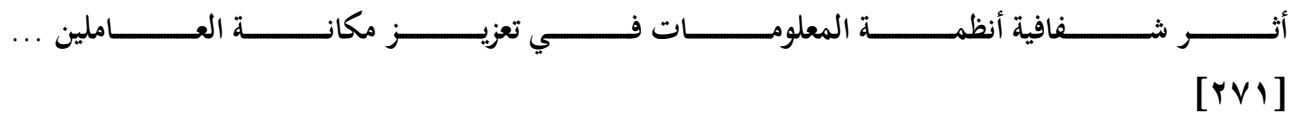

3. Dickson, Peter R., \& James L., 1987, Market Segmentation, Product Differentiation and Marketing Strategy, Journal Of Marketing, Vol. 51 ,April., No:3

4. Durbin, A.J., 1990, Effective Business Psycology, Prentice - Hill, Inc., USA .,

5. Fung ,Archon ,Graham ,Mary And Weil David ,2003,"The Political Economy Of Transparency : What Makes Disclosure Polices Sustainable? Harved University.

6. Goyal, D.P ,1998, Management Information Systems Concept And Application" Deep And Deep Publications New Delhi

7. Iyengar ,J,V, 1997, Information Value- Anutility Approach ", Journal of Computer information System, Winter

8. Kotler,P.1997,"MarketingManagementAnalysis, Planning ,Implementation And Control, $9^{\text {th }}$.Ed, Prentice- Hall ,Inc, USA.

9. Nihal Jaya Wichrama ,2001,Transparency And Accountability For Piblic Financial Integrity, McGraw-Hill, Co., New York.

10. Tarca ,Ann,2001,"International Convergence Of Accounting Practices : Choosing Between Lass And Gaap ", University Of New Soath Wales.

11. Vishwanath, Tra, Amd Kaufmann, Daniel ,1999," Towards Transparency In Finance And Governance, Thewortd Bank .

12. Witt, Stephen F.\& Moutinho luiz 1995, Tourism Marketing And Management - Hand Book, Prentice - Hill International $1^{\text {st }}$. Ed, U.K.

ثالثاً الانترنت

1.WWW.alwarak .com

2. WWW. Transparency.org

3. WWW.undp.com 